\title{
Site-Selective Artificial Ribonucleases: Oligonucleotide Conjugates Containing Multiple Imidazole Residues in the Catalytic Domain
}

\author{
Natalia G. Beloglazova, ${ }^{1}$ Martin M. Fabani, ${ }^{2}$ Nikolai N. Polushin, ${ }^{3}$ \\ Vladimir V. Sil'nikov, ${ }^{1}$ Valentin V. Vlassov, ${ }^{1}$ Elena V. Bichenkova, ${ }^{2}$ and Marina A. Zenkova ${ }^{1}$ \\ ${ }^{1}$ Institute of Chemical Biology and Fundamental Medicine, Siberian Branch of the Russian Academy of Sciences, \\ Novosibirsk 630090, Russia \\ ${ }^{2}$ School of Pharmacy and Pharmaceutical Sciences, The University of Manchester, Manchester M13 9PL, UK \\ ${ }^{3}$ Fidelity Systems Inc., 7961 Cessna Avenue, Gaithersburg, MD 20879, USA
}

Correspondence should be addressed to Marina A. Zenkova, marzen@niboch.nsc.ru

Received 7 April 2011; Accepted 5 July 2011

Academic Editor: Dmitry A. Stetsenko

Copyright (C) 2011 Natalia G. Beloglazova et al. This is an open access article distributed under the Creative Commons Attribution License, which permits unrestricted use, distribution, and reproduction in any medium, provided the original work is properly cited.

\begin{abstract}
Design of site-selective artificial ribonucleases (aRNases) is one of the most challenging tasks in RNA targeting. Here, we designed and studied oligonucleotide-based aRNases containing multiple imidazole residues in the catalytic part and systematically varied structure of cleaving constructs. We demonstrated that the ribonuclease activity of the conjugates is strongly affected by the number of imidazole residues in the catalytic part, the length of a linker between the catalytic imidazole groups of the construct and the oligonucleotide, and the type of anchor group, connecting linker structure and the oligonucleotide. Molecular modeling of the most active aRNases showed that preferable orientation(s) of cleaving constructs strongly depend on the structure of the anchor group and length of the linker. The inclusion of deoxyribothymidine anchor group significantly reduced the probability of cleaving groups to locate near the cleavage site, presumably due to a stacking interaction with the neighbouring nucleotide residue. Altogether the obtained results show that dynamics factors play an important role in site-specific RNA cleavage. Remarkably high cleavage activity was displayed by the conjugates with the most flexible and extended cleaving construct, which presumably provides a better opportunity for imidazole residues to be correctly positioned in the vicinity of scissile phosphodiester bond.
\end{abstract}

\section{Introduction}

The idea of site-selective artificial ribonucleases which are capable of cleaving any particular RNA sequence in vitro and in vivo, is a very attractive approach as, apart from being useful tools in molecular biology, these chemical ribonucleases are anticipated to be helpful for target validation, and even for the development of potential antiviral or anticancer therapeutics. The idealized site-selective artificial ribonuclease would be a compound that is easily synthesized, chemically stable, targeted to any chosen RNA sequence, and highly efficient in cleaving of the phosphodiester bonds. The oligonucleotide-based artificial ribonucleases seem to meet the majority of these criteria due to the fact that they can be directed to almost any desired RNA region in a site specificmanner by controlling the sequence of the oligonucleotide recognition part.

Virtually all types of the reactive groups, which are known to catalyze RNA scission, have been exploited for design and preparation of artificial ribonucleases [1-3]. Conjugates of oligonucleotides and RNA cleaving groups can be synthesized using two main approaches: incorporation of a catalytic structure in the oligonucleotide in the course of standard synthesis or by postsynthetic derivatization of an unprotected oligonucleotide [4]. Several alternative procedures for each strategy are available. The first approach often involves the automated oligonucleotide synthesis, when phosphoramidites of suitably protected nucleosides and 
catalytic groups are used as building blocks. Monomeric building blocks containing various metal complexes [5-8] or imidazole-based structures [9-16] have been previously proposed for the synthesis of the oligonucleotide-based artificial ribonucleases. The successive synthesis of oligonucleotide and catalytic structures of conjugates on the same solidphase support is a promising variation of this approach [1719]. However, this approach is inappropriate for the majority of the potential users of the conjugates due to the necessity to synthesize the unique phosphoramidite derivatives of the corresponding catalytic structures in each particular case, which creates the problems associated with the choice of appropriate protection groups and the deprotection procedure.

Various RNA-cleaving catalysts have been tethered to the $5^{\prime}$-terminus of oligonucleotides. However, the available synthetic methods, except for a few examples [20], allow the incorporation of only a single functional moiety per phosphoramidite unit. Generally, 5'-tethering can be implemented in two ways either by direct incorporation of a suitably protected and activated constructs into the $5^{\prime}$-terminus at the end of standard solid phase synthesis or by postsynthetic derivatization. In the former case, synthesis of highly modified oligonucleotides may become somewhat problematic because increase in a number of incorporations is expected to substantially decrease the overall yield of the conjugated oligonucleotides. Alternatively, a precursor molecule can first be formed by reacting the $5^{\prime}-\mathrm{OH}$ group of an assembled oligonucleotide with a heterobifunctional reagent (first modifier) bearing both the phosphoramidite moiety and a reactive group. The reactive group of the precursor oligonucleotide is then postsynthetically derivatized with an appropriate functional additive (second modifier) $[21,22]$. This precursor strategy has the obvious advantage that the same parent compound can be used to synthesize a number of differently tethered products. The first generation of oligonucleotide-based artificial ribonucleases, which was prepared using the precursor technique, has recently been reported to display high cleaving activity $[23,24]$. The precursor approach seems to be advantageous for the synthesis of libraries of oligonucleotide conjugates containing different functional groups.

However, the cleavage activity of these artificial ribonucleases so far has been inferior to the natural counterparts in terms of targeting and/or cleavage efficiency. We anticipate that the high level of efficiency of RNA cleavage by these oligonucleotide-based artificial ribonucleases can only be achieved if the optimal arrangement of all groups involved in the binding and catalysis is accomplished. It might be possible to improve on this by iterative design of the binding and cleavage domains by taking into account the optimal structures of the cleaving groups and their mutual spatial orientations against the RNA target. The structural organisation of artificial ribonucleases and the dynamic behavior of their cleaving constructs seem to be the key factors contributing to the cleavage activity of these compounds.

Several years ago, we reported a new type of oligonucleotide-based aRNases containing bis-imidazole cleaving constructs, which were prepared by precursor technique. It was demonstrated that these highly active bis-imidazole cleaving constructs were extremely flexible and the cleavage of the phosphodiester bond seemed to be a random event, which happened with the high efficiency every time, when these catalytic groups approached the scissile phosphodiester bond $[23,24]$. In the present paper, we use the developed precursor approach to synthesize the scaffolds of aRNases with the systematically varied structure of the cleaving constructs bearing multiple imidazole residues in the catalytic part. We demonstrate here that some of these conjugates exhibit remarkably high cleavage activity within the tRNA ${ }^{\text {Phe }}$ conjugate hybrid and identify possible location(s) of cleaving group(s) relative to the scissile ${ }^{5 \prime} \mathrm{C} 63-\mathrm{A} 64$ site. We also show, here, that the cleaving activity of the conjugates is governed by the intrinsic properties of the catalytic constructs, but not the detailed structure of the DNA:RNA hybrid, which was the same in all experiments.

\section{Materials and Methods}

2.1. General Chemicals. All buffers used in the experiments were prepared using milliQ water, contained $0.1 \mathrm{mM}$ EDTA, and were filtered through filters with pore size $0.22 \mu \mathrm{m}$ (Millipore). $\left[5^{\prime}{ }^{32} \mathrm{P}\right]-\mathrm{pCp}$ was from Biosan Co., Russia. T4 RNA ligase was purchased from Fermentas (Lethuania). Oligonucleotides TGGTGCGAATTCTG (A) and GATCGAACACAGGACCT (B) were synthesized on ASM-700 DNA Synthesizer (Biosset, Russia) by standard solid-phase phosphoramidite procedure. Yeast tRNA ${ }^{\text {Phe }}$ was a generous gift from Dr. G. Keith (Institut de Biologie Moléculaire et Cellulaire du CNRS, Strasbourg, France). Methoxyoxalamido (MOX) modifiers $\mathbf{M}$ used for conjugate synthesis were prepared as described in $[21,24]$.

\subsection{Synthesis of Oligonucleotide Conjugates B-Im(n) Type 1,} Type 2, Type 3, and Type 4. Deoxyribooligonucleotide B (GATCGAACACAGGACCT) was synthesized using standard solid-phase phosphoramidite chemistry, except that the $\mathrm{dC}^{\mathrm{Bz}}$-phosphoramidite was replaced with the $\mathrm{dC}^{\mathrm{Ac}}$-phosphoramidite. At the end of the automatic synthesis, the core 17-mer was coupled with one of the modifiers $\mathbf{M}$ (Type 1, Type 2, Type 3, or Type 4; see Figure 1) in $0.2 \mathrm{M}$ in acetonitrile for $15 \mathrm{~min}$. The prepared oligonucleotide MOX precursors were then functionalized with $2 \mathrm{M}$ solution of histamine in dimethylformamide for $3 \mathrm{hrs}$ at $20^{\circ} \mathrm{C}$ at constant shaking followed by deprotection with ammonia to produce the oligonucleotide conjugates containing multipleimidazole catalytic structures. The conjugates were purified by electrophoresis in $16 \%$ polyacrylamide/ $8 \mathrm{M}$ urea gel under denaturing conditions. The purified conjugates were analyzed by ESI and/or MALDI MS (calculated and experimental values of molecular masses are listed in Figure 1). In the cases when MALDI-MS analysis did not produce the expected mass spectra due to the conjugate fragmentation upon analysis, the conjugates were analyzed by electrophoresis under denaturing conditions (Figure 1(c)) and by HPLC (primary data not shown). Conjugates were designated as B-Im(N/m), where B-Im corresponds to the oligonucleotide $\mathrm{B}$ and shows that Im are in catalytic part, $\mathrm{N}$ is the number of 


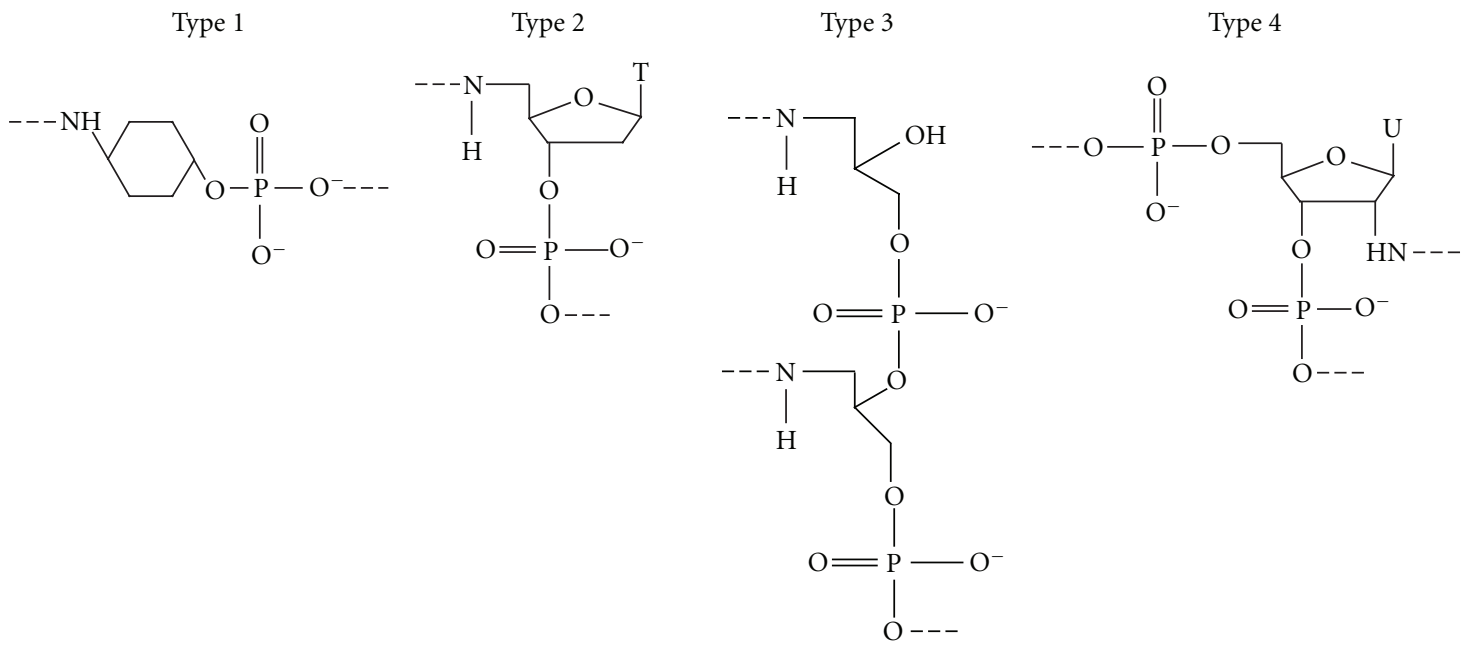

(a)

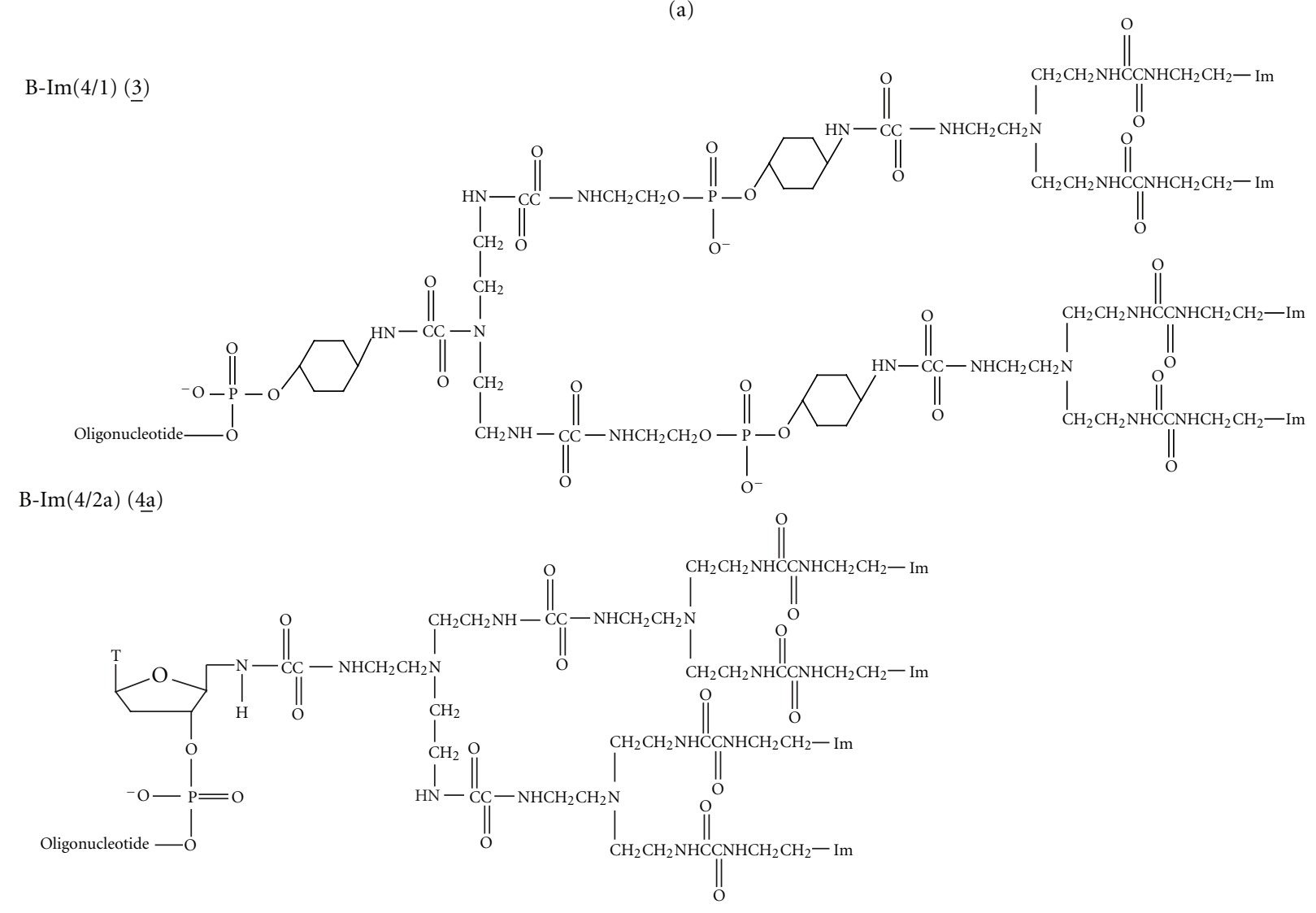

B-Im(4/2b) (마)

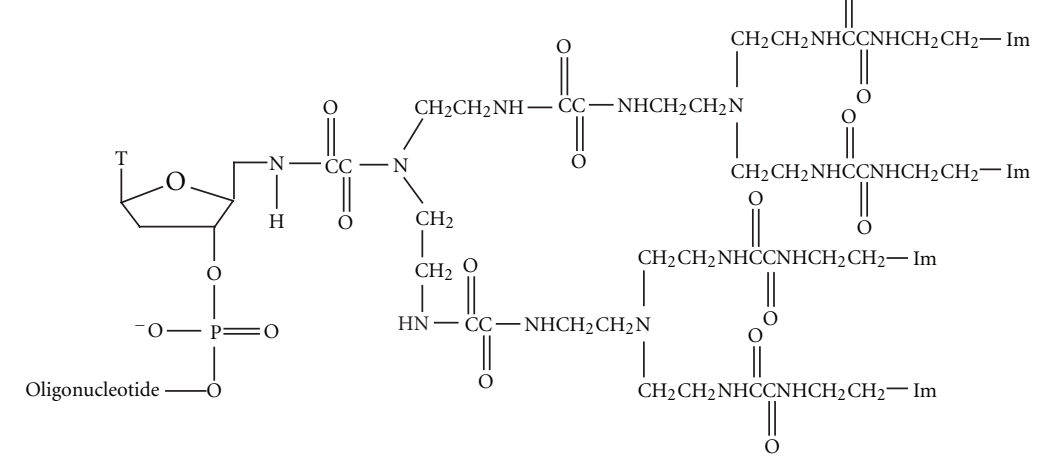

Figure 1: Continued. 


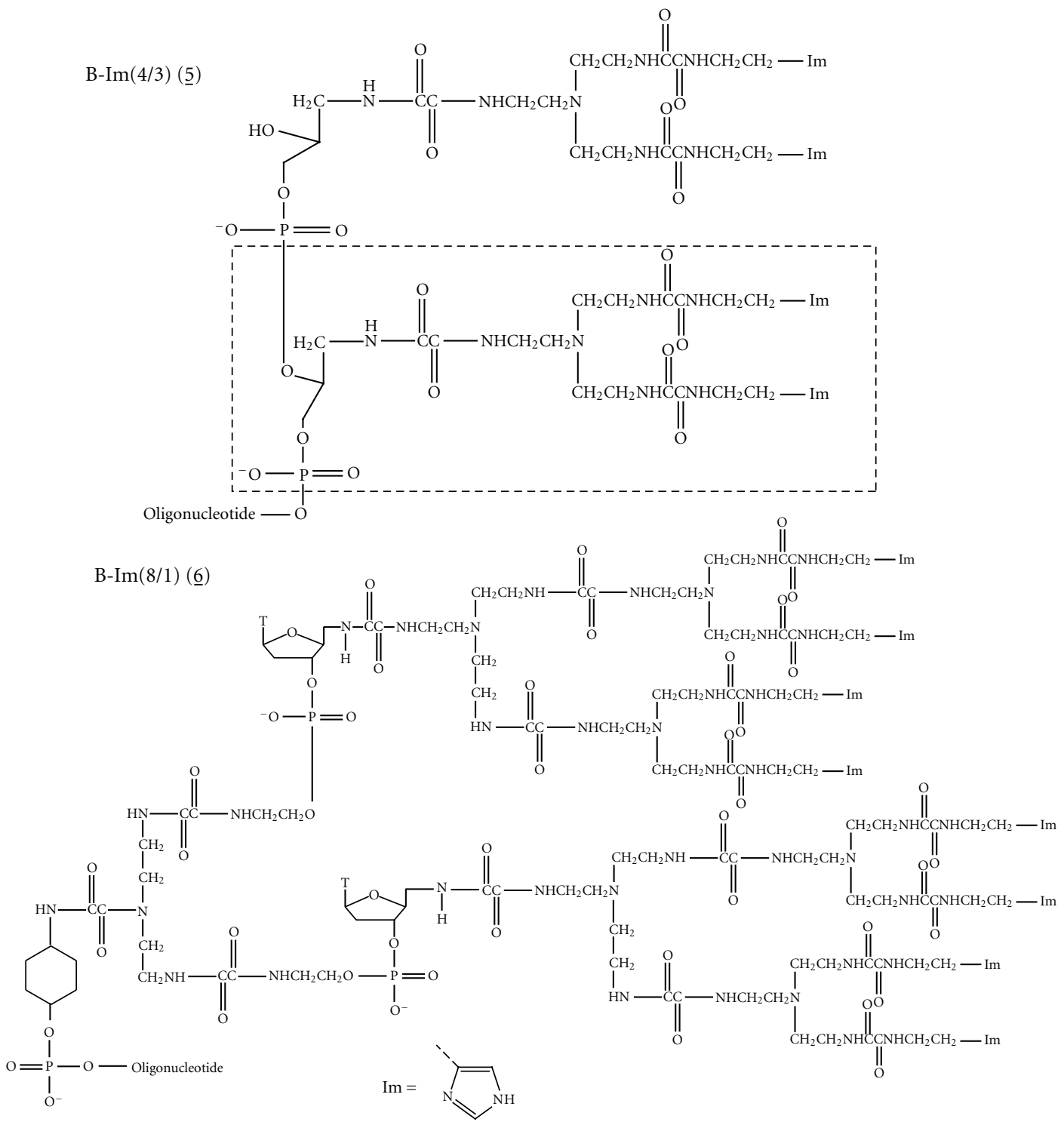

(b)

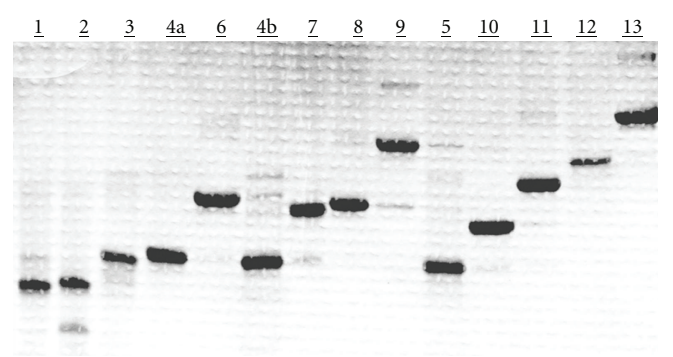

(c)

FIGURE 1: Schematic representation of the catalytic structures of the site-selective artificial ribonucleases B-Im( $/ / m)$ and analysis of the conjugates. (a) Anchor groups used for attachment of dendrimeric RNA-cleaving constructs to oligonucleotide B $5^{\prime}$-phosphate. (b) Schematic representation of conjugates bearing four and eight imidazole residues and anchor groups of Type1, Type 2, and Type 3, obtained using precursor technology. Mass spectrometry data: $\underline{\mathbf{1}}$ : calculated mass 5523.30, found mass 5523.73; $\underline{2}$ : 5566.80/5566.39; $\underline{3}$ : 5692.89/5692.03; $\underline{4 a:}$ : 6838.95/ 6838,$65 ; \underline{5}: 6423.63 / 6425.03$. (c) Analysis of the conjugates B-Im(N/m) by $12 \%$ polyacrylamide/ $8 \mathrm{M}$ urea gel electrophoresis. $0.1 \mathrm{~A}_{260}$ unit of each conjugate was applied on the gel; the conjugates were visualized in the gel by staining with Stains-All. Numbers on the top of the gel correspond to numeration of the conjugates in the Table 1 and Figure 1(b) and Supplementary Material Figure 1. 
imidazole residues (from 2 to 32 ), and $m$ corresponds to the type of anchor group $(1,2,3$, or 4; see Figure 1(a)).

2.3. Cleavage of $t R N A^{\text {Phe }}$ with Oligonucleotide Conjugates. $\left[3^{\prime}-32 \mathrm{P}\right]-\mathrm{tRNA}{ }^{\text {Phe }}$ was prepared and purified as described in [24]. $3^{\prime}$-end labeled tRNA was dissolved in water and stored at $-20^{\circ} \mathrm{C}$. Specific radioactivity of the $\left[{ }^{32} \mathrm{P}\right]-\mathrm{tRNA}^{\text {Phe }}$ was $5 \times 10^{5} \mathrm{cpm} /$ pmole.

Standard reaction mixture $(10 \mu \mathrm{L})$ contained imidazole buffer ( $50 \mathrm{mM}$ imidazole buffer, pH 7.0, $200 \mathrm{mM} \mathrm{KCl}$, $0.1 \mathrm{mM}$ EDTA, $100 \mu \mathrm{g} / \mathrm{mL}$ total tRNA from Escherichia coli as carrier), $5 \times 10^{-7} \mathrm{M}\left[3^{\prime}{ }^{32} \mathrm{P}\right]$-tRNA ${ }^{\mathrm{Phe}}$, and one of oligonucleotide conjugates $\mathrm{B}-\mathrm{Im}(\mathrm{N} / \mathrm{m})$ at concentrations ranging from $5 \times 10^{-7}$ to $5 \times 10^{-4} \mathrm{M}$ (as indicated in the legends in the figures). Reactions were carried out at $37^{\circ} \mathrm{C}$ and were quenched by precipitation of tRNA and tRNA fragments with $150 \mu \mathrm{L}$ of $2 \%$ lithium perchlorate solution in acetone. RNA was collected by centrifugation and dissolved in loading buffer $(6 \mathrm{M}$ urea, $0.025 \%$ bromophenol blue, $0.025 \%$ xylene cyanol). tRNA cleavage products were analyzed by electrophoresis in $12 \%$ polyacrylamide/ $8 \mathrm{M}$ urea gel. To identify cleavage sites, an imidazole ladder [24] and a Gladder produced by partial tRNA cleavage with RNase T1 [25] were run in parallel. To obtain quantitative data, the gel was dried and analyzed using Molecular Imager FX (BioRad). The total extent of RNA cleavage was determined as a ratio of radioactivity found in the tRNA fragments to total radioactivity applied on the gel lane.

To measure the kinetics of the tRNA cleavage with the oligonucleotide conjugates $\mathbf{B}-\operatorname{Im}(\mathbf{N} / \mathbf{m})$, the reaction mixture of $100 \mu \mathrm{L}$ was prepared containing imidazole buffer, $5 \times$ $10^{-7} \mathrm{M} 3^{\prime}-\left[{ }^{32} \mathrm{P}\right]-\mathrm{tRNA}{ }^{\text {Phe }}$ and one of the oligonucleotide conjugates B-Im(N/m) at different concentrations (from $5 \times$ $10^{-7}$ to $\left.5 \times 10^{-4} \mathrm{M}\right)$. Reaction was performed at $37^{\circ} \mathrm{C}$. At indicated time intervals, an aliquot $(10 \mu \mathrm{L})$ of the reaction mixture was withdrawn and frozen for lately assay. Reaction aliquots were defrosted and immediately precipitated with $150 \mu \mathrm{L} 2 \%$ lithium perchlorate in acetone. After that, the reaction mixtures were assayed as described above.

In some experiments, imidazole buffer was replaced by HEPES-buffer (50 mM HEPES-KOH, pH 7.0; $0.2 \mathrm{M} \mathrm{KCl,}$ $0.1 \mathrm{mM}$ EDTA, $100 \mu \mathrm{g} / \mathrm{mL}$ RNA-carrier), or Cacodylate buffer (50 mM Cacodylic acid-KOH, pH 7.0; $0.2 \mathrm{M} \mathrm{KCl}$, $0.1 \mathrm{mM}$ EDTA, $100 \mu \mathrm{g} / \mathrm{mL}$ RNA-carrier) or Tris-HCl-buffer (50 mM Tris- $\mathrm{HCl}, \mathrm{pH} \quad 7.0 ; 0.2 \mathrm{M} \mathrm{KCl}, 0.1 \mathrm{mM}$ EDTA, $100 \mu \mathrm{g} / \mathrm{mL}$ RNA-carrier). The experiments where imidazole buffer was replaced by other buffers are indicated in text and figure legends.

2.4. Inhibition of Site-Selective $t R N A^{\text {Phe }}$ Cleavage by Oligonucleotide Competitor. In the competition experiments, to a reaction mixtures $(10 \mu \mathrm{L})$ containing imidazole buffer, $\left.5 \times 10^{-7} \mathrm{M}^{\prime}{ }^{\prime}-{ }^{32} \mathrm{P}\right]$-tRNA ${ }^{\text {Phe }}$ oligonucleotide A (complementary to sequence $62-76$ of the tRNA ${ }^{\text {Phe }}$ ) or oligonucleotide $\mathbf{B}$ was added up to concentration $5 \times 10^{-5} \mathrm{M}$. The mixtures were incubated for $10 \mathrm{~min}$ at $37^{\circ} \mathrm{C}$, then one of oligonucleotide conjugates $B-\operatorname{Im}(N / m)$ at concentration $5 \times$ $10^{-6} \mathrm{M}$ was added and the mixtures were incubated at $37^{\circ} \mathrm{C}$ for different times (from $30 \mathrm{~min}$ to $2 \mathrm{~h}$ ). Reaction was quenched and analyzed as described above.

2.5. Gel-Mobility Shift Assay of Hybridization of Oligonucleotide $B$ and Conjugates B-Im(4/2) to $t R N A^{\text {Phe }}$. A gel-mobility shift assay of $\mathrm{tRNA}^{\text {Phe }}$ binding with oligonucleotide $\mathbf{B}$ and conjugates $B-\operatorname{Im}(4 / 2)$ was performed as follows. $\left[3^{\prime}{ }^{32} \mathrm{P}\right]$ tRNA $\left(5 \times 10^{-7} \mathrm{M}\right)$ was incubated at $37^{\circ} \mathrm{C}$ during $30 \mathrm{~min}$ in reaction mixture $(10 \mu \mathrm{L})$ containing hybridization buffer (50 mM Tris-HCI, pH 7.0, $200 \mathrm{mM} \mathrm{KCI,} 0.1 \mathrm{mM}$ EDTA) and oligonucleotide $\mathrm{B}$ or conjugate $\mathrm{B}-\operatorname{Im}(4 / 2)$ ranging in concentration from $1 \times 10^{-7}$ to $5 \times 10^{-6} \mathrm{M}$. After incubation, $8 \mu \mathrm{L}$ of loading buffer ( $50 \%$ glycerol, $0.025 \%$ bromophenol blue, 0.025 xylene cyanol) was added to each probe and probes were immediately applied onto running native $10 \%$ PAGE with $100 \mathrm{mM}$ Tris-borate, $\mathrm{pH} 8.3$ as running buffer preequilibrated at $4^{\circ} \mathrm{C}$ for $3 \mathrm{~h}$. Electrophoresis was performed at $4^{\circ} \mathrm{C}$ for $5 \mathrm{~h}$ at $450 \mathrm{~V}$. To obtain quantitative data, the gel was dried and analyzed using Molecular Imager FX (Bio-Rad).

2.6. Molecular Modelling. Molecular modelling was performed using SYBYL 6.6 (TRIPOS Inc.) on a Silicon Graphics $\mathrm{O} 2$ workstation as described in [24]. All calculations (MM/MD) were carried out in vacuo using Kollman-All force field parameters and a distance-dependent dielectric constant equal to 4 . The building of the model molecules (see Figure 1) was carried out in three stages. First, an A-like DNA:RNA hybrid was built using BIOPOLYMER/SYBYL 6.6. Second, the catalytic fragments $\operatorname{Im}(4 / 1), \operatorname{Im}(4 / 2 a)$, and $\operatorname{Im}(\mathbf{4} / \mathbf{2 b})$ were built using SKETCH/SYBYL 6.6. Charge distributions for these constructs were calculated using a semiempirical MO program, MOPAC, after geometric optimization. In the last step, each the corresponding cleaving fragment was attached to the DNA:RNA hybrid via the terminal 5 '-phosphate group of the G1 nucleotide residue.

For each molecule, several different starting structures were created, differing in the conformation and location of the cleaving group, ranging from "in" to "out" extreme positions relative to the DNA:RNA hybrid. The starting structures of each molecule were subjected to minimization to a gradient convergence of $0.05 \mathrm{Kcal} / \mathrm{mol}$, considering the DNA:RNA hybrid as a solid body. Each starting structure was individually subjected to a 12 ps MD run using simulated annealing as follows. The system was heated at $600 \mathrm{~K}$ during 2 ps followed by a gradual cooling down to $100 \mathrm{~K}$ over 10 ps. A final minimization to convergence criteria was performed resulting in the respective final conformations for each type of molecule. $\mathrm{S}$ and $\mathrm{F}$ symbols before the conjugate name indicate the starting and final conformation, respectively.

"Active conformations" were obtained for each model molecule (O1-Im4/1, O2-Im4/1 O1-Im4/2a, O2-Im4/2a, O1-Im4/2b, and O2-Im4/2b, where Type1 shows the anchor group 1) using a similar simulating annealing protocol. In these molecules, the cleaving groups were deliberately located in the most favorable position for successful cleavage at the $\mathrm{C}_{63}-\mathrm{A}_{64}$ site. Namely, the distance between $\mathrm{N} 1$ of one of the imidazole residues and $2^{\prime} \mathrm{OH}$ group of $\mathrm{C}_{63}$ was $\sim 3 \AA$ and the distance between $\mathrm{N} 1$ of the other imidazole residue and 
TABLE 1: Oligonucleotide-based artificial ribonucleases bearing multiple imidazole groups in the catalytic part: structure of conjugates and efficiencies of site-specific cleavage of yeast tRNA ${ }^{\text {Phe }}$.

\begin{tabular}{|c|c|c|c|c|c|c|}
\hline & Conjugate $^{1}$ & Number of Im groups & Anchor group $^{2}$ & Linker length ${ }^{3}$ & Reaction rate, $\% / 1 \mathrm{~h}^{4}$ & Reaction $_{1 / 2} \tau^{5}$ \\
\hline 1 & B- $\operatorname{Im}(2 / 1)$ & 2 & $1 / 2$ & 21 & 24.8 & $2 \mathrm{~h} 15^{/ *}$ \\
\hline 2 & $\mathrm{~B}-\operatorname{Im}(2 / 2)$ & 2 & 2 & 20 & 25.3 & $2 \mathrm{~h} 5^{/ *}$ \\
\hline 3 & $\mathrm{~B}-\operatorname{Im}(4 / 1)$ & 4 & 1 & 41 & 49.8 & $1 \mathrm{~h} 5^{\prime}$ \\
\hline $4 \mathrm{a}$ & $B-\operatorname{Im}(4 / 2 a)$ & 4 & 2 & 29 & 16.6 & $2 \mathrm{~h} 50^{\prime}$ \\
\hline $4 \mathrm{~b}$ & B- $\operatorname{Im}(4 / 2 b)$ & 4 & 2 & 26 & 5.5 & $>12 \mathrm{~h}$ \\
\hline 5 & $\mathrm{~B}-\operatorname{Im}(4 / 3)$ & 4 & 3 & $18 / 22$ & $\sim 1$ & $-^{6}$ \\
\hline 6 & $\mathrm{~B}-\operatorname{Im}(8 / 1)$ & 8 & 1 & 41 & 45.1 & $1 \mathrm{~h} 15^{\prime}$ \\
\hline 7 & $\mathrm{~B}-\operatorname{Im}(8 / 2)$ & 8 & 2 & 41 & 29.7 & $2 \mathrm{~h}$ \\
\hline 8 & $\mathrm{~B}-\operatorname{Im}(8 / 2+1)$ & 8 & 1 & 49 & 31.3 & $1 \mathrm{~h} 45^{\prime}$ \\
\hline 9 & B- $\operatorname{Im}(16 / 1)$ & 16 & 1 & 70 & 38.5 & $2 \mathrm{~h} 10^{\prime}$ \\
\hline 10 & $\mathrm{~B}-\operatorname{Im}(8 / 4+1)$ & 8 & 4 & $23 / 31 / 41$ & 29.1 & $2 \mathrm{~h}$ \\
\hline 11 & $\mathrm{~B}-\operatorname{Im}(12 / 4+2)$ & 12 & 4 & $23 / 31 / 51$ & 33.8 & $1 \mathrm{~h} 40^{\prime}$ \\
\hline 12 & B- $\operatorname{Im}(24 / 4+2)$ & 24 & 2 & $41 / 79$ & 49.9 & $1 \mathrm{~h}$ \\
\hline 13 & $\mathrm{~B}-\operatorname{Im}(32 / 4+2)$ & 32 & 1 & $41 / 98$ & 20 & $2 \mathrm{~h} 30^{\prime}$ \\
\hline
\end{tabular}

${ }^{1}$ The structures of the conjugates are shown in Figure 1 and in Supplementary material (SM-Figure 1).

${ }^{2}$ The type of anchor groups of the conjugates as shown in Figure 1(a). Type 1: cyclohexanol moiety; 2: 5' -aminothymidine residue; 3: nonnucleotide insertion; 4: $2^{\prime}$-modified uridine residue.

${ }^{3}$ The number of simple C-C, C-N, or P-O bonds between the $5^{\prime}$-terminal phosphate group of oligonucleotide B and imidazole groups of RNA-cleaving construct.

${ }^{4}$ Efficiency of the RNA cleavage was measured as percentage of tRNA ${ }^{\text {Phe }}$ cleavage at $\mathrm{C}_{63}-\mathrm{A}_{64}$ phosphodiester bond achieved after incubation during $1 \mathrm{~h}$ in the presence of $10 \mu \mathrm{M}$ of the conjugate.

${ }^{5}$ Time to reach $50 \%$ of tRNA cleavage under the standard conditions (see above) at conjugates concentration $10^{-5} \mathrm{M}$.

$650 \%$ of tRNA ${ }^{\text {Phe }}$ cleavage was not achieved under experimental conditions.

* These conjugates are described in the preceding paper [1].

the oxygen of the phosphate group, connecting $\mathrm{C}_{63}$ and $\mathrm{A}_{64}$, was around $3 \AA[26,27]$. A final minimization was performed without constraints, using the above protocol.

\section{Results and Discussion}

3.1. Design of Oligonucleotide-Based Artificial Ribonucleases. The RNA cleaving oligonucleotide conjugates have been prepared in two-step procedure described in $[21,22]$. In the first step, the precursor 17-mer GATCGAACACAGGACCT (B) was built up with multiple methoxyoxalamido (MOX) modifiers of different type (see Supplementary Material available online at doi:10.4061/2011/748632 for the structures of all conjugates synthesized in this study). In the second step, the prepared oligonucleotide-MOX precursors were functionalized with histamine to yield after deprotection step the oligonucleotide conjugates B-Im(N/m), bearing from 4 to 32 histamine residues at the $5^{\prime}$-end.

Figure 1 provides structures of oligonucleotide conjugates $B-\operatorname{Im}(4 / n)$ and $B-\operatorname{Im}(8 / 1)$ studied in this work. The conjugates hereafter were referred to as $\mathbf{B}-\operatorname{Im}(\mathbf{N} / \mathbf{m})$, where $\mathrm{B}$-Im designates the oligonucleotide-imidazole conjugates, $\mathrm{N}$ shows the number of imidazole residues, and $\mathrm{m}$ indicates the type of anchor group. In the cases, when two or three conjugates contain equal number of imidazole residues and the same anchor group, the conjugate number is shown in the brackets. The distance between oligonucleotide and imidazole residues of the cleaving part was varied by altering the structures of the anchor and the linker groups.
Cyclohexyl residue was exploited as anchor group in the conjugate Type 1 . Thymidine nucleoside was used to anchor the catalytic part in the conjugate Type 2 . The thymidine nucleoside, presenting in the structure of conjugate, was supposed to be involved in base pairing with RNA or might be stacked on heteroduplex contributing to the duplex stability. In the conjugate Type 3, an anchor group was chemical construct mimicking phosphodiester bond and used as a rule as nonnucleotide insertion in oligonucleotide. Type 4 anchor group was used in the conjugates $\underline{10}-\underline{13}$ to increase the number of branches, bearing imidazole residues. For this purpose and to increase the linker length and flexibility, the anchor groups of Types 1 and 2 were incorporated also into the linker structures (see Figure 1-SM, conjugates $\underline{\mathbf{6}}-\underline{9}$ and $\underline{11}-\underline{13}$ ). Moreover, the length and structure of linkers, connecting imidazole residues and anchor, were distinguished sufficiently among the compounds (Table 1 and Figure 1-SM). Conjugates containing equal number of imidazole residues, for example, B-Im(4/m) or B-Im(8/m), differ not only in anchor groups, but also in a linker length. The linker of conjugate $B-\operatorname{Im}(4 / 3)$ was the shortest one. In this conjugate, four imidazole residues were placed nonsymmetrically in respect to the phosphate groups forming the anchor, which connected the oligonucleotide $\mathbf{B}$ and the cleaving construct.

The identity of the conjugates was confirmed by massspectrometry; (see Figure 1). In addition, the purity of the conjugates was confirmed by electrophoresis in 12\% PAAM/ $8 \mathrm{M}$ urea gel (Figure $1(\mathrm{c})$ ). It is seen that the purity of the conjugates is close to $95 \%$. Only in the case of conjugates 2 , 
$\underline{\mathbf{5}}, \underline{\mathbf{1 0}}$, and $\underline{\mathbf{1 6}}$, some other bands with the relative intensities of $5-7 \%$ are seen.

3.2. Cleavage of Yeast tRNA ${ }^{\text {Phe }}$ by the Conjugates Bearing Multiple Imidazole Residues. Yeast tRNA ${ }^{\text {Phe }}$ was chosen deliberately as a target to assess cleavage activity of the conjugates. The rationale behind this was that other oligonucleotidebased aRNases including three prepared using precursor approach had been tested using this target $[1,12,14-16,28]$. Figure 2(a) represents cloverleaf structure of yeast tRNA ${ }^{\text {Phe }}$ showing the target site for the conjugates $\mathbf{B}-\mathbf{R}(\mathbf{N} / \mathbf{m})$. The recognition element of the studied aRNases was represented by the 17-mer oligonucleotide $\mathbf{B}$, which was complementary to the sequence 44-60 and was designed to deliver the imidazole residues to the sequence ${ }^{61} \mathrm{CACAG}^{65}$ in the T-arm of the tRNA ${ }^{\text {Phe }}$, which is known to be highly sensitive towards cleavage [29-32]. It was previously shown that oligonucleotide $\mathbf{B}$ could efficiently bind to this sequence in the tRNA ${ }^{\text {Phe }}$, which resulted in unfolding of entire T $\Psi C$ hairpin, whereas the aminoacceptor and anticodon stems of the tRNA were only slightly affected by the oligonucleotide binding [33-35].

The conjugates $\mathbf{B}-\mathbf{I m}(\mathbf{N} / \mathbf{m})$ were designed to catalyze RNA cleavage via transesterification reaction. To compare the ribonuclease activities of the conjugates, we used the conditions of single reaction turnover $([\mathbf{B}-\mathbf{I m}(\mathbf{N} / \mathbf{m})]>[\mathrm{RNA}])$. The oligonucleotide part of the conjugate provides efficient hybridization with target sequence in RNA $^{\text {Phe }}$ and formation of the stable heteroduplex $\left(\mathrm{K}_{d}=7 \mu \mathrm{M} \pm 1 \mu \mathrm{M}\right.$; V. Petyuk, unpublished data). We believe that under the experimental conditions the rate and efficiency of site-selective cleavage of the target is affected only by the catalytic part of the conjugate.

Site-selective cleavage of $\left[3^{\prime}-{ }^{32} \mathrm{P}\right] \mathrm{tRNA} \mathrm{R}^{\text {Phe }}$ by the conjugates was carried out at $37^{\circ} \mathrm{C}$ in $50 \mathrm{mM}$ imidazole buffer. The reaction was initiated by addition of the conjugate $\mathrm{B}-\operatorname{Im}(\mathrm{N} / \mathrm{m})$ to the reaction mixtures. Localization of cleavage sites was performed by comparison of products obtained upon cleavage of tRNA by the conjugates with the products of random RNA cleavage with RNase T1 and $2 \mathrm{M}$ imidazole buffer, pH $7.0[25,36]$. Figure 2(b) shows typical results of the analysis of tRNA ${ }^{\text {Phe }}$ cleavage by the conjugates B$\operatorname{Im}(\mathbf{N} / \mathbf{m})$ at $37^{\circ} \mathrm{C}$ under standard conditions. No measurable spontaneous degradation of tRNA under the experimental conditions in the absence of reagents and in the presence of unmodified parent oligonucleotide B occurred (Figure 2(a), lanes $\mathrm{C} 1$ and $\mathrm{C} 2$ ). The conjugates cleave tRNA ${ }^{\text {Phe }}$ with high rate mostly at the phosphodiester bonds C63-A64 and A64G65. The extents of $\mathrm{RNNA}^{\text {Phe }}$ cleavage at these bonds are about $70 \%$ and $20 \%$, respectively. Moreover, some minor cleavage at the phosphodiester bonds C61-A62 and A62-C63 within the target sequence is observed (Figure 2(a), lanes 110). The ratio between the products of tRNA cleavage at these phosphodiester bonds located in close proximity to each other in the target sequence seems to correspond to steric accessibility of these bonds to cleavage by the conjugates B-Im(N/m). In the case of conjugate B-Im(4/2a) (similar cleavages were observed for the conjugates with 16, 24, and 32 imidazole residues), slight cleavages are observed at
U8-A9 and C75-A76 phosphodiester bonds (less then 3\% of the total extent of tRNA cleavage), known as well as C61$\mathrm{A} 62$ and C63-A64 bonds in the yeast tRNA ${ }^{\text {Phe }}$ to be very sensitive toward cleavage by various agents [29-32]. The bond U8-A9 is located in the proximity to sequence C61-G65 if tertiary structure of tRNA ${ }^{\text {Phe }}$ is taken into account. Thus, one may assume that the observed cleavage of this bond occurs in complementary complex formed by conjugate B- $\operatorname{Im}(\mathbf{N} / \mathbf{m})$ with tRNA and is the result of flexibility of RNAcleaving group of the conjugates. Besides, we can assume that initial cleavage of phosphodiester bond C63-A64 produces a nick in tRNA molecule that may increase the flexibility of the complex tRNA-conjugate $\mathbf{B}-\operatorname{Im}(\mathbf{N} / \mathbf{m})$ and thus makes phosphodiester bonds C64-G65 and U8-A9 available for catalyst's function groups. The slight cleavage observed at C75-A76 site apparently is the result of spontaneous tRNA hydrolysis in the duplex with the conjugate.

Competition experiments were used to prove that tRNA cleavage occurs in $t R N A$-conjugate complex. RNAA $^{\text {Phe }}$ cleavage by conjugate $B-\operatorname{Im}(4 / 1)$ was performed in the presence of oligonucleotide inhibitors of two types: parent oligonucleotide B and oligonucleotide A complementary to the sequence 61-75 (Figure 2(b), lanes 17-19). As expected, the cleavage of tRNA ${ }^{\text {Phe }}$ by conjugate $\mathrm{B}-\operatorname{Im}(4 / 1)$ is considerably decreased in the presence of oligonucleotides B (primary data not shown) and is completely abolished in the presence of oligonucleotide $\mathbf{A}$, which protects target sequence by duplex formation. It is worth noting that in the presence of oligonucleotides $\mathbf{B}$, the cleavage of tRNA ${ }^{\text {Phe }}$ is suppressed in all sites due to competitive binding, whereas oligonucleotides A inhibit tRNA ${ }^{\text {Phe }}$ cleavage only at the target sequence failing to change reaction rate at other sites. These results indicate the structural specificity of cleavage and stress the fact that the cleavage occurs only at a single-stranded target sequence.

Figure 2(c) shows concentration dependencies of the cleavage reaction for conjugates $\mathrm{B}-\operatorname{Im}(4 / 1)(\underline{3})$ and $\operatorname{Im}(24 /$ 4+2) (11) (curves 1 and 2, resp.) and binding of the conjugate B-Im(4/2a) and parent oligonucleotide B with tRNA (curves 3 and 4, resp.). It is seen that the cleavage data are in agreement with the complex formation. Furthermore, the binding affinity of the parent oligonucleotide and the conjugate studied under identical conditions are found to be similar (Figure 2(c)). Therefore, the conjugation of bulky imidazolecontaining reactive groups to the oligonucleotide does not affect the hybridization process.

To estimate the influence of buffer on efficiency of site-selective RNA cleavage, we compared tRNA ${ }^{\text {Phe }}$ cleavage by the conjugate $B-\operatorname{Im}(4 / 2)$ in different buffer solutions (Figure 2(d)), taken $50 \mathrm{mM}$ imidazole buffer, $\mathrm{pH} 7.0$ as a standard conditions. The rate of site-selective cleavage is affected by replacement of $50 \mathrm{mM}$ imidazole buffer, $\mathrm{pH}$ 7.0, by $50 \mathrm{mM}$ Tris- $\mathrm{HCl}$ buffer or $50 \mathrm{mM}$ cacodylate buffer at $\mathrm{pH} 7.0$ by the factor of 1.5 indicating that imidazole itself may contribute to cleavage reaction. At longer incubation time, this difference became insignificant and does not exceed estimated experimental error. Surprisingly, $50 \mathrm{mM}$ HEPES buffer entirely abolishes cleavage inactivating the conjugates. The reason of this is not entirely understood. 


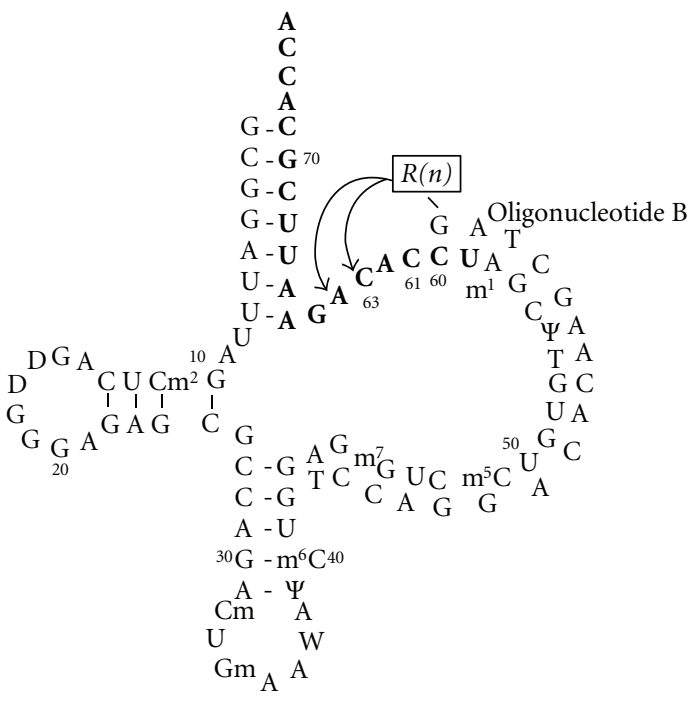

(a)

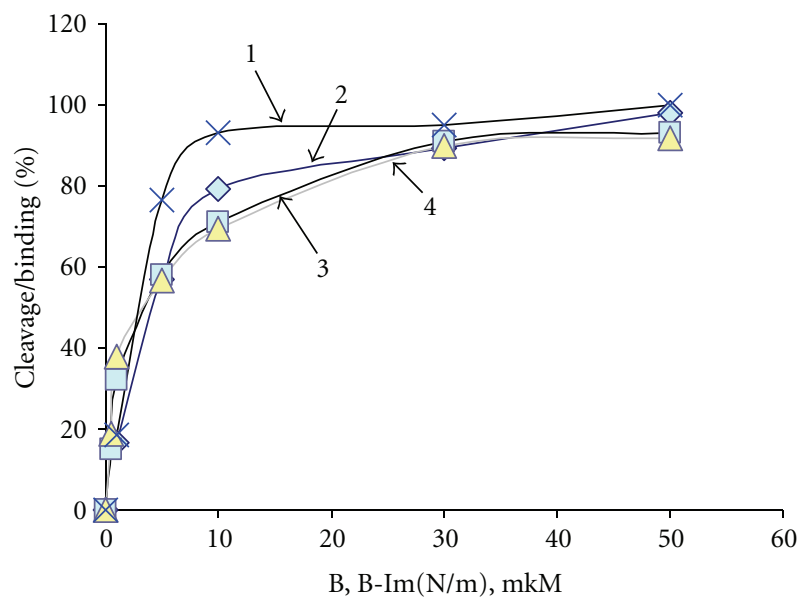

(c)

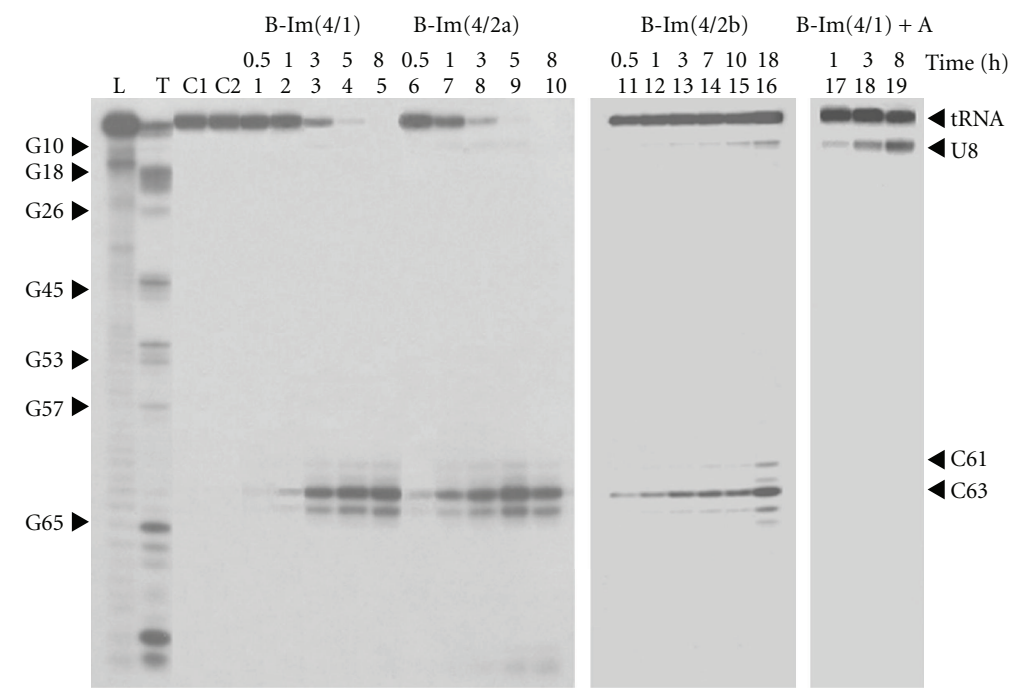

(b)

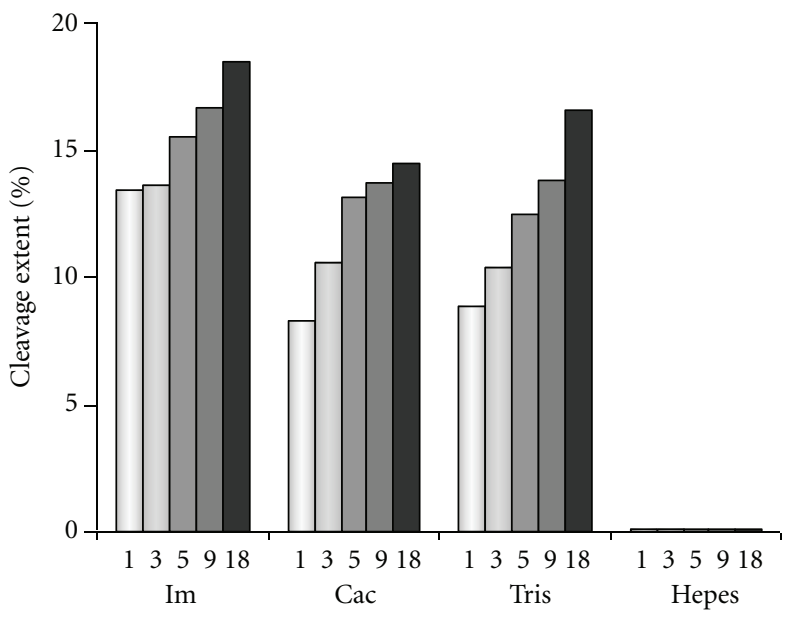

(d)

FIGURE 2: Site-selective cleavage of yeast tRNA ${ }^{\text {Phe }}$ by the oligonucleotide conjugates bearing multiple imidazole residues in the catalytic part. 
One explanation could be that sulfonic acid of HEPES [4-(2hydroxyethyl)-piperazine-1-ethanesulfonic acid] may interact with protonated imidazole residues of the conjugates and inactivate it. Previously, we also observed twofold decrease of the rate of RNA cleavage by oligonucleotide conjugate bearing two imidazole residues in $50 \mathrm{mM}$ HEPES-KOH buffer, whereas the other buffers only slightly affected the rate of RNA cleavage [37].

In Figure 2, (a) represents cloverleaf structure of yeast tRNA $^{\text {Phe }}$ and target sequences for oligonucleotide B-based artificial ribonucleases $\mathbf{B}-\mathbf{I m}(\mathbf{N} / \mathbf{m})$. Bold letters show target sequence for oligonucleotide-competitor A. Arrows indicate the sites of site-selective tRNA cleavage by the conjugates; (b) represents cleavage of $\mathrm{tRNA}^{\text {Phe }}$ with oligonucleotide conjugates B-Im(4/m). Autoradiograph of $12 \%$ polyacrylamide $/ 8 \mathrm{M}$ urea gel. Cleavage reactions were performed at $37^{\circ} \mathrm{C}$ in $50 \mathrm{mM}$ imidazole buffer, $\mathrm{pH} \mathrm{7.0,} \mathrm{containing} 200 \mathrm{mM} \mathrm{KCl}$, $0.2 \mathrm{mM}$ EDTA, $100 \mu \mathrm{g} / \mathrm{mL}$ RNA carrier, $5 \times 10^{-7} \mathrm{M}\left[3^{\prime}-\right.$ $\left.{ }^{32} \mathrm{P}\right] \mathrm{tRNA}^{\mathrm{Phe}}$ and $1 \times 10^{-5} \mathrm{M}$ one of the conjugates $\mathrm{B}-\operatorname{Im}(4 / 1)$, B-Im(4/2a), and B-Im(4/2b). Lanes L and T1 are Imidazole and RNase T1 ladders, respectively. Lanes $\mathrm{C} 1$ and $\mathrm{C} 2$ are tRNA incubated in the reaction buffer for $8 \mathrm{~h}$ in the absence and in the presence of oligonucleotide $\mathbf{B}\left(5 \times 10^{-5} \mathrm{M}\right)$, respectively. tRNA cleavage by conjugate $B-\operatorname{Im}(4 / 1)(\underline{3})$ for $0.5,1,3,5$, and $8 \mathrm{~h}$ (lanes $1-5$, resp.), by conjugate B$\operatorname{Im}(4 / 2 \mathrm{a})(\underline{4 a})$ for $0.5,1,3,5$, and $8 \mathrm{~h}$ (lanes $6-10)$, by the

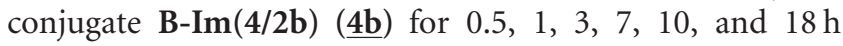
(lanes 11-16); by the conjugate $\mathrm{B}-\operatorname{Im}(4 / 1)(\underline{3})$ in the presence of oligonucleotide $\mathbf{A}\left(1 \times 10^{-4}\right)$ for $0.5,1$, and $5 \mathrm{~h}$ (lanes 17-19). Concentration of the conjugates in the reaction mixtures was $1 \times 10^{-5} \mathrm{M}$. Reactions were quenched and analyzed as described in the experimental part; (c) represents concentration dependencies of the $\mathrm{RRNA}^{\text {Phe }}$ cleavage by the conjugates B-Im(4/1) (프) and B-Im(24/2) (12) (curves 1 and 2, resp.) and complex formation with the conjugate $\mathbf{B}-\operatorname{Im}(4 /$ 2a) (4a) (curve 3) and parent oligonucleotide B (curve 4). The reaction mixtures were incubated for $2 \mathrm{~h}$ under the conditions described above; (d) represents the influence of the buffer nature on the rate of RNA $^{\text {Phe }}$ cleavage by the conjugate $\mathbf{B}-\operatorname{Im}(\mathbf{4} / \mathbf{2 a})(\underline{\mathbf{4 a}}) \cdot\left[3^{\prime}-{ }^{32} \mathrm{P}\right] \mathrm{tRNA}^{\text {Phe }}(0.5 \mu \mathrm{M})$ was incubated with $2 \mu \mathrm{M}$ of $(\underline{\mathbf{4 a}})$, in $50 \mathrm{mM}$ imidazole buffer, $\mathrm{pH} 7.0(\mathrm{Im})$ or $50 \mathrm{mM}$ cacodylate buffer, pH 7.0 (Cac) or $50 \mathrm{mM}$ Tris-HCl buffer, $\mathrm{pH} 7.0$ (Tris) or $50 \mathrm{mM}$ HEPES buffer, pH 7.0 (Hepes) containing $0.2 \mathrm{M} \mathrm{KCl}, 0.2 \mathrm{mM}$ EDTA, and $0.1 \mathrm{mg} / \mathrm{mL}$ RNA carrier.

\subsection{Kinetics of $t R N A^{\text {Phe }}$ Cleavage by the Conjugates.} Figure 3(a) displays the kinetics of $\mathrm{tRNA}^{\text {Phe }}$ cleavage with conjugates under the study taken at conjugate concentration $10 \mu \mathrm{M}$. It is seen that the conjugates cleave RNA with different efficacy. One of the most effective conjugate is B-Im(4/1), as complete site-selective cleavage of the target by this conjugate is achieved within 2-3 hours. Similar kinetics are displayed by the conjugate $\mathbf{B}-\operatorname{Im}(\mathbf{8} / \mathbf{1})(\underline{\mathbf{6}})$ and the $B-\operatorname{Im}(24 / 4+2)(\underline{12})$. The conjugates $B-\operatorname{Im}(4 / 2 a)(4 a)$ and $\mathbf{B}-\operatorname{Im}(8 / 2)(\underline{7})$ catalyze RNA cleavage less efficiently as compared with B-Im(4/1) or B-Im(8/1). Cleavage efficiency of the conjugate $\mathrm{B}-\operatorname{Im}(4 / 3)(\underline{5})$ was essentially poor.
Figure $3(\mathrm{~b})$ shows kinetic curves of tRNA ${ }^{\text {Phe }}$ cleavage by conjugate B-Im(4/1) obtained at different concentrations of the conjugate. The character of kinetic curves evidences the bimolecular reaction: the rate of RNA cleavage is increased with the increasing of the conjugate concentrations. At concentration of conjugate $\mathbf{B}-\operatorname{Im}(4 / 1)$ of $10 \mu \mathrm{M}$, which provides its almost quantitative binding to tRNA, the half-life of tRNA is about $1 \mathrm{~h}$ (Figure $3(\mathrm{~b})$, curve " $10 \mu \mathrm{M}$ "). When concentration of conjugate $\mathbf{B}-\operatorname{Im}(\mathbf{4 / 1})$ is increased up to $50 \mu \mathrm{M}$, the half-life of tRNA is counted by minutes (Figure 3(b), curve " $50 \mu \mathrm{M}$ "). It should be noted that the site-selective cleavage of tRNA proceeds much slower than the binding of the parent oligonucleotide $\mathbf{B}$ to tRNA under similar conditions [33-35]. At concentration of the conjugate equal to or twice as higher as concentration of the tRNA, the curves reveal lag period (Figure $3(\mathrm{~b})$, curves " 0.5 " and " $1 \mu \mathrm{M}$," resp.) indicating that the process of site-selective RNA cleavage includes several consecutive steps occurring with comparable rates. Another explanation of this could be that the reaction has more complex character and goes through some stages other than binding of the conjugate and cleavage, which results in sigmoid-like kinetic curve.

For conjugate B-Im(4/1), we calculated the association rate and cleavage rate constants from the data shown in Figure 3(b), assuming that cleavage of the tRNA occurs within the complex with the conjugate. In this case, hybridization step is the second-order reaction and cleavage stage is intramolecular first-order reaction. It turns out that cleavage pe se occurs 50 times faster than the binding of the conjugate with the complementary sequence within RNA target (association rate constant and cleavage rate constant are $(0.074 \pm 0.002) \mathrm{M}^{-1} \mathrm{~s}^{-1}$ and $(3.4 \pm$ $0.55) \times 10^{-3} \mathrm{~s}^{-1}$, resp.). In other word, binding of the conjugate with tRNA is the rate-limiting stage of site-selective RNA cleavage.

3.4. Correlations between Structure and Activity of the Conjugates Bearing Multiple Imidazole Groups. The conjugates display different cleavage activities (Table 1) ranging from very high cleavage rate $\left(\tau_{1 / 2} \sim 1 \mathrm{~h}\right.$ in the case of $\left.\mathrm{B}-\operatorname{Im}(4 / 1)\right)$ to very low $\left(\tau_{1 / 2}\right.$ value was not achieved under the experimental conditions in the case of B-Im(4/3)). Remarkable cleaving activity of the conjugates $\underline{\mathbf{3}}, \underline{\mathbf{6}}$, and $\underline{\mathbf{1 2}}$ as well as moderate cleavage activity of the conjugates $\underline{4 a}, \underline{8}, \underline{10}, \underline{11}$, and $\underline{13}$ and poor efficiency of the conjugate $\underline{\mathbf{5}}$ are likely resulted from the differences in the structure of the catalytic part of the conjugates rather than due to different hybridization properties and the cleavage reaction pe se. The conjugates under the study contain identical oligonucleotide recognition element and display similar cleavage specificity with only minor differences in the cleavage pattern. Therefore, neither hybridization nor sensitivity of the phosphodiester bonds toward the cleavage could explain the differences in the catalytic properties of the conjugates. Even the catalytic parts of the conjugates in several cases contain the equal number of imidazole residues.

Table 1 summarizes data on the cleavage activity and structure of the conjugates under the study (linker length in 


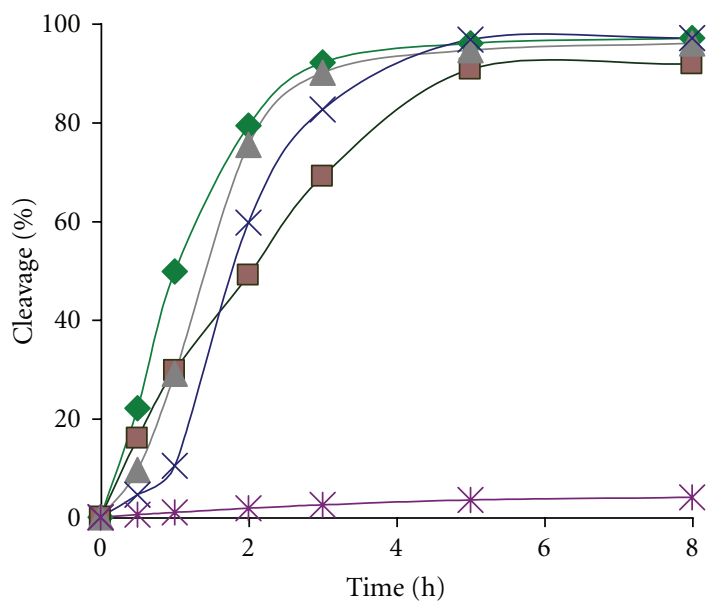

(a)

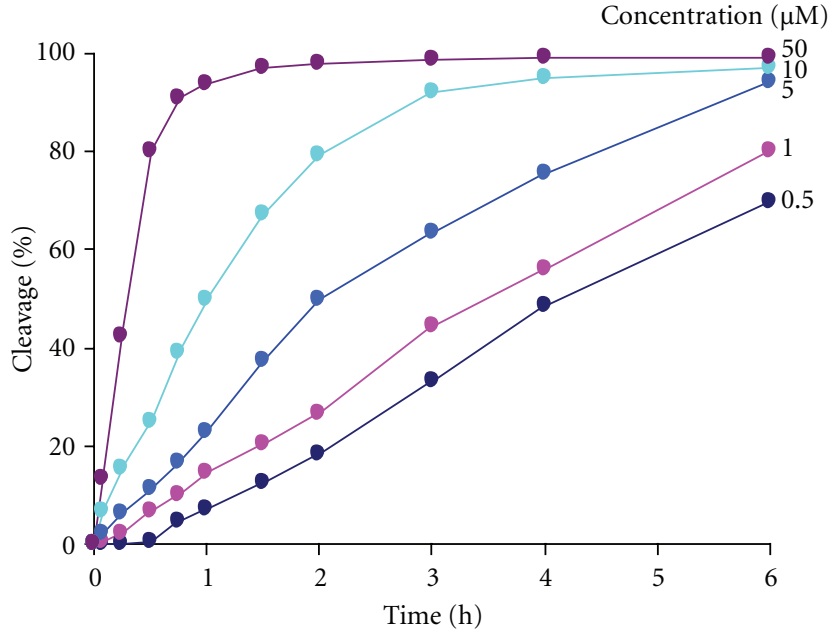

(b)

Figure 3: Kinetics of tRNA ${ }^{\text {Phe }}$ cleavage by the conjugates: (a) tRNA cleavage by B-Im(4/1) (ㅁ) (rhombs), B-Im(4/2a) (4a) (squares), B-Im(4/3) ( $\underline{\mathbf{5}})$, (asterisks), B-Im(8/4+1) (10) (triangles), and B-Im(24/4+2) (12) (crosses) under standard conditions at conjugates concentration $10 \mu \mathrm{M}$. (b) tRNA cleavage by $\mathbf{B}-\operatorname{Im}(4 / 1)(\underline{3})$ at concentrations ranging from 0.5 to $50 \mu \mathrm{M}$.

total number of simple $\mathrm{C}-\mathrm{C}, \mathrm{C}-\mathrm{N}, \mathrm{C}-\mathrm{O}$, and $\mathrm{P}-\mathrm{O}$ bonds between $5^{\prime}$-end of oligonucleotide $\mathrm{B}$ and imidazole residues, type of anchor group, and reaction halftimes). It is seen that hydrolytic activity of compounds is in a good agreement with the length of their linkers (Table 1). Amongst the conjugates bearing four imidazole residues, the highest cleavage activity is observed for the conjugate $B-\operatorname{Im}(4 / 1)$, which has the linkers of 41 simple bonds. The conjugates B-Im(4/2a) with the linkers of 29 chemical bonds exhibit 3-fold lower cleavage activity, whereas B-Im(4/3) (18/24 bonds) cleaves tRNA with lowest efficiency. Thus, stepwise shortening of a linker part of conjugate B-Im(4/m) from 41 to 18/24 simple bonds results in decreasing of cleavage efficiency from $50 \%$ per hour to $1 \%$ per hour. As it is seen from Table 1, only the conjugates containing the linkers of 40 simple bonds are capable of efficiently catalyzing cleavage of $\mathrm{tRNA}^{\text {Phe }}$ in a site-selective manner. Thus, we can conclude that a long flexible linker of 40 or more simple $\mathrm{C}-\mathrm{C}, \mathrm{C}-\mathrm{N}$, or $\mathrm{P}-\mathrm{O}$ bonds is required for efficient site-selective cleavage of RNA target.

Figure 4 display Structure-Activity correlations found for the conjugates $\mathbf{B}-\operatorname{Im}(\mathbf{N} / \mathbf{m})$. It is seen that cleavage activity of the conjugates $\mathbf{B}-\mathbf{I m}(\mathrm{N} / \mathbf{1})$ depends on the number of imidazole groups in the catalytic part (Figure 4(a)). The conjugates bearing 4 and 8 imidazole residues exhibit the highest cleavage activity, while increasing of the number of imidazole groups inhibits cleavage. It is worth pointing out that sigmoidicity of kinetic curves taken under identical conditions is increased with increasing of the number of imidazoles in the conjugate (primary data not shown). It is likely that cleavage activity of these conjugates is affected by a steric interference between imidazoles, thus leading to a loss of cleavage rate. Therefore, four (and/or eight) imidazole residues in the catalytic part of the conjugate seem to be sufficient for efficient RNA cleavage.

From the data shown in Figure 4(b), it is seen that ribonuclease activity of the conjugates depends on type of the anchor group used for attachment of parent oligonucleotide to RNA-cleaving construct. The conjugates with Type 1 anchor group (B-Im(N/1)), cyclohexyl moiety (Figure 1(a)), display higher cleavage activity than conjugates with the anchor group in a form of thymidine residue (Type 2, Figure 1) and especially than conjugates with a nonnucleoside anchor group (Type 3, Figure 1) (Table 1). The difference between cleavage activity of the conjugates with Type 2 and Type 4 anchor groups does not exceed experimental error, but is reliably lower than that for conjugates with Type 1 anchor group. Thus, the structure and flexibility of the linker part, the number of imidazole residues in the catalytic part, and the type of anchor group affect cleavage activity of the conjugates and play a role in the optimal positioning of the catalyst in respect to scissile phosphodiester bond.

3.5. Molecular Modeling Study. The main goal of the molecular modelling was to clarify the following issues.

(1) Is there any preferable orientation(s) of the cleaving group(s) in the vicinity of the cleavage site, which could explain the hydrolytic activity (or its absence) of each conjugate?

(2) Is there any evidence of interaction(s) between the cleaving constructions and the DNA:RNA hybrid, which could stabilize preferable orientation(s) of these groups near the cleavage site?

(3) What is the correlation between the structure of the cleaving constructs and the linker groups and their hydrolytic activity?

It is evident from the biochemical assays that hydrolytic activity within the heteroduplex $t R N A{ }^{\text {Phe }}$-conjugate is governed by the intrinsic properties of the cleaving constructs, but not the detailed structure of the DNA-RNA hybrid, which was the same in all experiments. Therefore, the main priority was to identify possible location(s) of the cleaving 


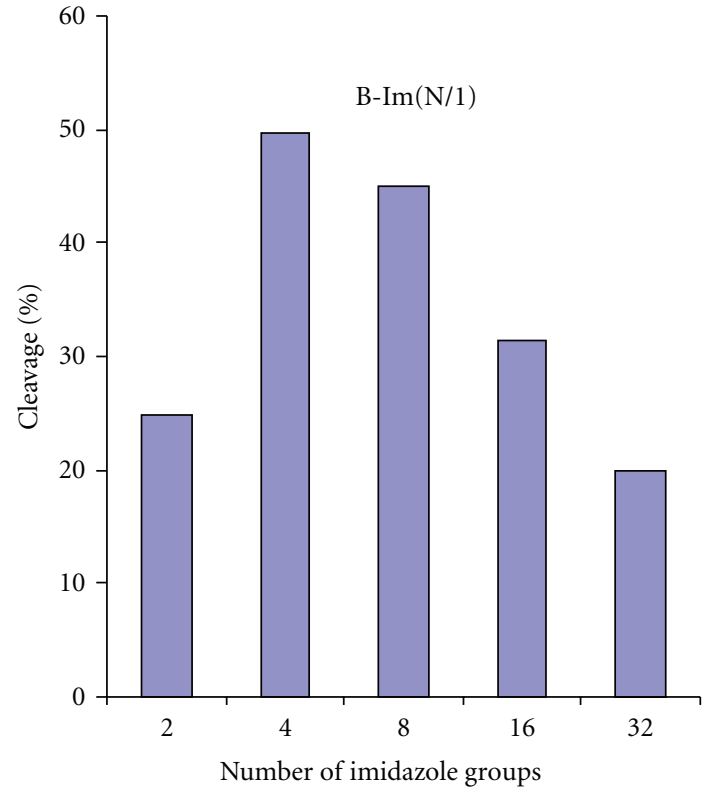

(a)

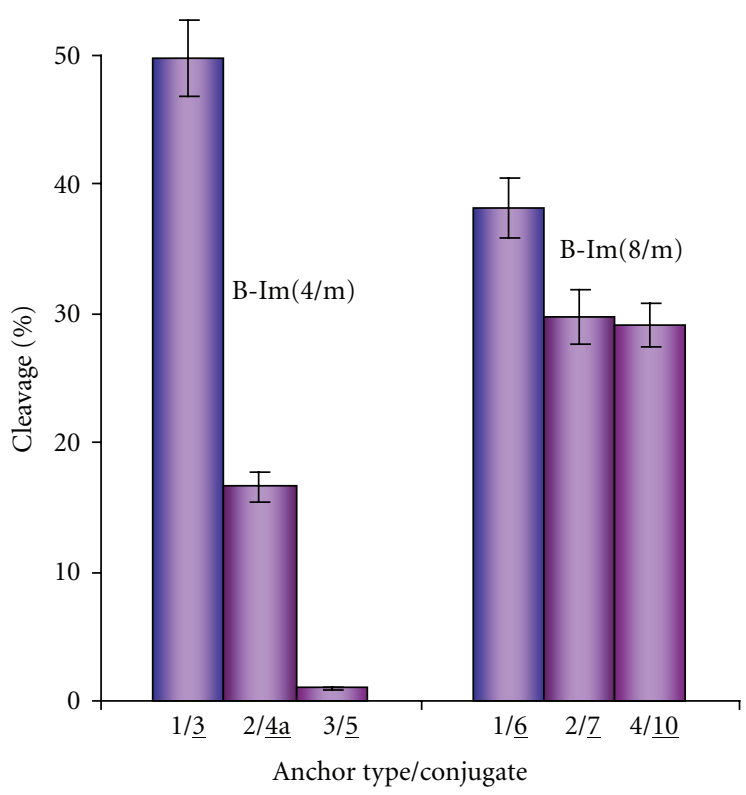

(b)

FIGURE 4: Structure-activity correlations found for the conjugates $\boldsymbol{B}-\mathbf{I m}(\mathbf{N} / \mathbf{m})$. (a) Correlations between the number of imidazole groups in catalytic parts of conjugates and their catalytic activities. Cleaving data corresponds to incubation of the RNA with conjugates $\underline{\mathbf{1}}, \underline{\mathbf{3}}, \underline{\mathbf{6}}, \underline{\mathbf{9}}$, and 13 under standard conditions for $1 \mathrm{~h}$. (b) Correlation between the type of anchor groups and catalytic activity of conjugates. Diagram presents data for tetraimidazole-containing conjugates $\underline{\mathbf{3}}, \underline{\mathbf{4 a}}, \underline{\mathbf{5}}(\mathbf{B}-\operatorname{Im}(\mathbf{4} / \mathbf{m}))$ and octaimidazoles-containing conjugates $\underline{6}, \underline{7}, \underline{10}(B-\operatorname{Im}(\mathbf{8} / \mathbf{m}))$.

group(s) relatively to the cleavage site rather than to determine the detailed conformation of the hybrid (which would be impossible in the absence of relevant NMR/X-ray data).

It has been shown earlier that hybridization of long oligonucleotides to TYC-loop $[33,38]$ or to the $3^{\prime}$-acceptor stem [33-35] of tRNA induced a local unfolding of the tRNA secondary structure. Therefore, we assumed that the hybrid part of the molecules under the study can be represented to a first approximation by a double-stranded DNA:RNA duplex, which would form primarily an A-like conformation, according to physicochemical investigations [39-41]. In our molecular modeling studies, we used a shortened model for the heteroduplex, comprising the target RNA sequence (corresponding to the ${ }^{5 \prime}$ A44-U69 fragment of tRNA ${ }^{\text {Phe }}$ ) and the oligodeoxyribonucleotide conjugate complementary to this RNA region (Figure 2(a)).

Based on this hybrid duplex, three model molecules were created $(\mathrm{M}-\operatorname{Im}(4 / 1), \mathrm{M}-\operatorname{Im}(4 / 2 \mathrm{a})$, and $\mathrm{M}-\operatorname{Im}(4 / 2 \mathrm{~b}))$ by attachment of the respective cleaving constructs to the $5^{\prime}$ terminal phosphate group of the $\mathrm{G}^{1}$ nucleotide residue (see Figures 1 and 2). At this stage, in the absence of the detailed structural data for the hybridized heteroduplex, it was reasonable to treat the hybrid as a "solid" structure [24] whilst allowing cleaving constructs to possess a full conformational flexibility during the calculations.

For each molecule $\mathrm{M}-\operatorname{Im}(4 / 1), \mathrm{M}-\operatorname{Im}(4 / 2 \mathrm{a})$, and $\mathrm{M}$ $\operatorname{Im}(4 / 2 \mathrm{~b})$, several starting structures were created differing in the spatial orientation of the cleaving construct(s), ranging from "in" to "out" extremes (see "Section 2"). This increased the conformational space searched for each model molecule.
All starting structures were subjected to independent simulating annealing (see "Section 2") giving rise to the respective final structures $(\mathrm{M}-\operatorname{Im}(4 / 1)$ : $\mathrm{F} 1-\operatorname{Im}(4 / 1)-\mathrm{F} 9-\operatorname{Im}(4 / 1)$; M-Im(4/2a): F1-Im(4/2a)-F9-Im(4/2a); M-Im(4/2b): F1$\operatorname{Im}(4 / 2 b)-F 9-\operatorname{Im}(4 / 2 b)$.

Both structural parameters and energy values of each final structure were analyzed and compared with those of "active" conformations (O1-Im(4/1), O2-Im(4/1), O1-Im(4/ 2a), O2-Im(4/2a), O1-Im(4/2b), and O2-Im(4/2b)), which had deliberately preorganized cleaving centers according to [20, 26, 27, 42, 43] (see "Section 2") (Table 2).

Molecules containing four imidazole residues $\mathrm{M}-\operatorname{Im}(4 /$ 1), $M-\operatorname{Im}(4 / 2 a)$, and $M-\operatorname{Im}(4 / 2 b)$, having two bis-imidazole cleaving constructs, differ in the geometrical properties of their linker groups (see Figure 1). The linker group of $\mathrm{M}-\operatorname{Im}(4 / 1)$ possess a cyclohexyl fragment connecting the cleaving moieties with the oligonucleotide. $\operatorname{In} M-\operatorname{Im}(4 / 2 a)$, the cyclohexyl fragment is replaced by a deoxyribothymidine fragment. $M-\operatorname{Im}(4 / 2 b)$ is a shorter analogue of $M-\operatorname{Im}(4 / 2 a)$.

For each molecule, nine final structures plus two "optimal" conformations were obtained as a result of the simulated annealing calculations. The data on the distances between $\mathrm{N} 1$ atoms of imidazole rings and target site as well as energy values are presented in Table 2.

For M-Im(4/1) (Table 2), the most energetically favorable conformations (O1-Im(4/1), O2-Im(4/1), and F4- $\operatorname{Im}(4 / 1))$ are characterized by the location of at least two imidazole groups close to the target site $(3-7 \AA)$. In the most cases, $M-\operatorname{Im}(4 / 2 \mathrm{a})$ conformers have at least one imidazole group located near the cleavage site, which suggests a high probability for cleaving groups to form a preorganized 
TABLE 2: Distances between active centers of the conjugates B-Im(4/m) and RNA target atoms.

\begin{tabular}{|c|c|c|c|c|c|c|c|c|}
\hline \multirow{2}{*}{ Molecule } & \multirow{2}{*}{ Final structure } & \multirow{2}{*}{ Energy $(\mathrm{kcal} / \mathrm{mol})$} & \multicolumn{2}{|c|}{$\Delta \mathrm{E}(\mathrm{kcal} / \mathrm{mol})$} & \multicolumn{2}{|c|}{ Dist. Pair 1(E) } & \multicolumn{2}{|c|}{ Dist. Pair 2(E) } \\
\hline & & & for $\mathrm{O} 1$ & for $\mathrm{O} 2$ & $\operatorname{Im} 1-\mathrm{OH}^{(\mathrm{a})}$ & $\operatorname{Im} 2-\mathrm{OP}^{(\mathrm{b})}$ & Im1-OH & $\operatorname{Im} 2-\mathrm{OP}$ \\
\hline \multirow{11}{*}{$M-\operatorname{Im}(4 / 1)$} & $\mathrm{F} 1-\operatorname{Im}(4 / 1)$ & 47.3 & 18.2 & 13 & 6.2 & 11.4 & 26.6 & 21 \\
\hline & F2- $\operatorname{Im}(4 / 1)$ & 66.7 & 37.6 & 32.4 & 6.2 & 14.3 & 21.1 & 22.9 \\
\hline & F3- $\operatorname{Im}(4 / 1)$ & 48.3 & 19.2 & 14.0 & 6.6 & 16.3 & 23.0 & 33.9 \\
\hline & $\mathrm{F} 4-\operatorname{Im}(4 / 1)$ & 28.6 & -0.6 & -5.8 & 7.1 & 7.0 & 2.9 & 7.5 \\
\hline & F5- $\operatorname{Im}(4 / 1)$ & 60.2 & 31.1 & 25.9 & 7.5 & 17.2 & 11.8 & 11.5 \\
\hline & F6- $\operatorname{Im}(4 / 1)$ & 42.6 & 13.5 & 8.3 & 12.8 & 9 & 23.1 & 13.4 \\
\hline & F7- $\operatorname{Im}(4 / 1)$ & 54.9 & 25.8 & 20.5 & 11.9 & 12.7 & 15.7 & 25.9 \\
\hline & F8- $\operatorname{Im}(4 / 1)$ & 47.3 & 18.2 & 13.0 & 7.3 & 15.0 & 24.8 & 21.0 \\
\hline & F9- $\operatorname{Im}(4 / 1)$ & 49.8 & 20.7 & 15.5 & 10.7 & 17.0 & 16.5 & 23.7 \\
\hline & $\mathrm{O} 1-\operatorname{Im}(4 / 1)$ & 29.1 & - & - & 3.0 & 3.0 & 12.9 & 23.1 \\
\hline & $\mathrm{O} 2-\operatorname{Im}(4 / 1)$ & 34.3 & - & - & 23.5 & 25.7 & 3.2 & 3.3 \\
\hline \multirow{11}{*}{$M-\operatorname{Im}(4 / 2 a)$} & F1- $\operatorname{Im}(4 / 2 a)$ & -6.7 & -4.3 & -5.8 & 12.4 & 25.1 & 26.4 & 19.8 \\
\hline & $\mathrm{F} 2-\operatorname{Im}(4 / 2 \mathrm{a})$ & 24.0 & 26.3 & 24.8 & 23.1 & 15.6 & 23.2 & 34.8 \\
\hline & F3- $\operatorname{Im}(4 / 2 a)$ & 0.5 & 2.9 & 1.4 & 21.1 & 11.6 & 21.3 & 19.8 \\
\hline & $\mathrm{F} 4-\operatorname{Im}(4 / 2 \mathrm{a})$ & 9.7 & 12.0 & 10.5 & 6.4 & 15.8 & 23.3 & 27.8 \\
\hline & F5- $\operatorname{Im}(4 / 2 a)$ & 1.7 & 4.0 & 2.5 & 5.6 & 10.1 & 21.6 & 26.7 \\
\hline & F6- $\operatorname{Im}(4 / 2 a)$ & 23.4 & 25.8 & 24.3 & 26.1 & 30.6 & 16.2 & 8.6 \\
\hline & F7- $\operatorname{Im}(4 / 2 a)$ & 23.4 & 25.8 & 24.3 & 26.1 & 30.6 & 16.2 & 8.6 \\
\hline & F8- $\operatorname{Im}(4 / 2 a)$ & 0.5 & 2.9 & 1.4 & 21.2 & 11.6 & 24.4 & 17.4 \\
\hline & F9- $\operatorname{Im}(4 / 2 a)$ & 13.3 & 15.6 & 14.1 & 14.4 & 18.4 & 28.2 & 27.8 \\
\hline & $01-\operatorname{Im}(4 / 2 a)$ & -2.4 & - & - & 3.17 & 3.0 & 20.1 & 33.7 \\
\hline & $\mathrm{O} 2-\operatorname{Im}(4 / 2 a)$ & -0.9 & - & - & 17.7 & 17.6 & 3.0 & 3.2 \\
\hline \multirow{11}{*}{$M-\operatorname{Im}(4 / 2 b)$} & $\mathrm{F} 1-\operatorname{Im}(4 / 2 \mathrm{~b})$ & -4.7 & 6.9 & -16.2 & 23.7 & 15.9 & 21.4 & 19.9 \\
\hline & $\mathrm{F} 2-\operatorname{Im}(4 / 2 \mathrm{~b})$ & -17.9 & -6.3 & -29.3 & 30.9 & 32.7 & 21.9 & 30.7 \\
\hline & F3- $\operatorname{Im}(4 / 2 b)$ & -17.8 & -6.2 & -29.2 & 27.6 & 36.0 & 25.9 & 21.9 \\
\hline & $\mathrm{F} 4-\operatorname{Im}(4 / 2 \mathrm{~b})$ & 0.1 & 11.7 & -11.3 & 5.3 & 23.3 & 14.5 & 14.3 \\
\hline & F5- $\operatorname{Im}(4 / 2 b)$ & -9.1 & 2.5 & -20.5 & 21.1 & 26.2 & 23.5 & 25.8 \\
\hline & F6- $\operatorname{Im}(4 / 2 b)$ & 0.1 & 11.7 & -11.3 & 18.5 & 9.2 & 11.3 & 19.7 \\
\hline & F7- $\operatorname{Im}(4 / 2 b)$ & 0.1 & 11.7 & -11.3 & 18.5 & 9.2 & 11.3 & 19.7 \\
\hline & F8- $\operatorname{Im}(4 / 2 b)$ & -6.7 & 4.9 & -18.1 & 9.0 & 10.6 & 20.7 & 23.3 \\
\hline & F9- $\operatorname{Im}(4 / 2 b)$ & -2.5 & 9.1 & -13.9 & 14.9 & 30.4 & 27.9 & 31.8 \\
\hline & 01-Type3 & -11.6 & - & - & 3.1 & 3.0 & 13.4 & 14.9 \\
\hline & O2-Type3 & 11.4 & - & - & 25.2 & 27.2 & 3.0 & 3.0 \\
\hline
\end{tabular}

(a) $\mathrm{Im} 1-\mathrm{OH}$ represents the distance between $\mathrm{N} 1$ of one of the imidazole residues and the $2^{\prime} \mathrm{OH}$ group of $\mathrm{C}^{63}$.

(b) Im2-OP represents the distance between $\mathrm{N} 1$ of the other imidazole residue and the oxygen of the phosphate group connecting $\mathrm{C}^{63}$ and $\mathrm{A}^{64}$.

"active" conformation. These data are in agreement with the biochemical assays on high hydrolytic activity seen for B- $\operatorname{Im}(4 / 2 a)$ conjugate, showing that this compound reaches the maximum activity $(49.8 \%)$ found for artificial ribonucleases. Figure 5 represents the fragments of the F4- $\operatorname{Im}(4 / 1)$ structure, as the most energetically favorable conformation of $\mathrm{M}-\operatorname{Im}(4 / 1)$, and shows the probable orientation of the cleaving groups.

In the case of $M-\operatorname{Im}(4 / 2 a)$, most of the final structures obtained in the simulated annealing experiments are characterized by a distant location of cleaving groups from the target site (Table 2). For example, the lowest-energy structures F1-Im(4/2a), F3-Im(4/2a), and F8-Im(4/2a) have very unfavorable orientations of imidazole cleaving groups in terms of hydrolytic activity (see Figure 6 showing F1-Im(4/ 2a) final structure as an example). The possible reason of this could be the presence of a deoxyribothymidine fragment linking the oligonucleotide and the cleaving construct. According to our data, the thymidine base is involved in the DNA:RNA helix structure in a semistacking interaction with the neighboring nucleotide residue $\mathrm{dG}^{1}$. The thymidine base matches comfortably the duplex structure, although no additional hydrogen bonding with the opposite strand was detected (for instance, with the $\mathrm{A}^{62}$ ). This interaction could control the overall conformation of the rest of the cleaving construct and possibly restrict the conformational freedom of this group, resulting in a decreased probability to render an "active" conformation. This could explain the relatively 
<smiles></smiles><smiles>CC(=O)C(C)COP(C)(=O)[O-]</smiles>

(a)<smiles></smiles><smiles>Cc1cn(NOP(C)(=O)[O-])cn1</smiles>

Scheme 1<smiles></smiles><smiles>CC(=O)NN(C)OC(C)=O</smiles><smiles></smiles><smiles></smiles>

(b)

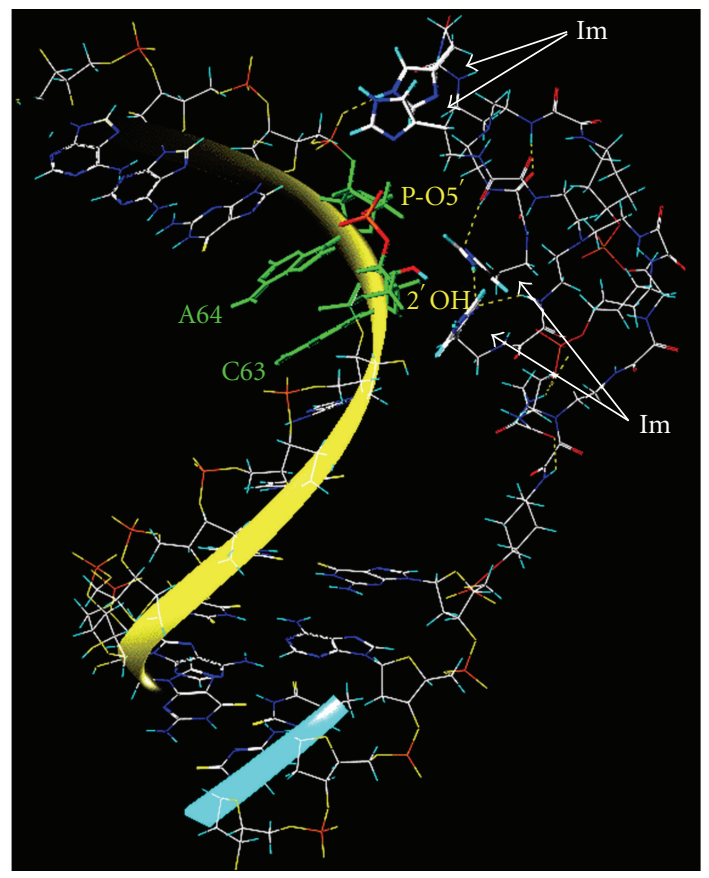

Figure 5: A fragment of the most favourable conformation, F4$\operatorname{Im}(4 / 1)$, found for hybrid complex $\mathrm{H}$ - $\operatorname{Im}(4 / 1)$ between artificial ribonuclease $\mathrm{B}-\operatorname{Im}(\mathbf{4} / \mathbf{1})$ and $\mathrm{tRNA}^{\text {Phe }}$ where the close proximity of imidazole cleaving groups to the target sequence $\mathrm{C}^{63}-\mathrm{A}^{64}$ (green) is evident. Hydrogen bonds are shown in yellow.

low hydrolytic activity of B-Im(4/2a) (16.6\%) compared to B-Im(4/1).

Even more pronounced decrease in hydrolytic activity (down to $5-7 \%$ ) was observed for conjugate B-Im(4/2b), a structural analogue of $\mathrm{B}-\operatorname{Im}(4 / 2 \mathrm{a})$ with a shortened linker group. Data obtained in biochemical assays are consistent with results from molecular modeling for M$\operatorname{Im}(4 / 2 \mathrm{~b})$ (Table 2$)$, showing that the most energetically favorable conformations (for instance, F2- $\operatorname{Im}(4 / 2 \mathrm{~b})$, F3$\operatorname{Im}(4 / 2 b)$, and $F 5-\operatorname{Im}(4 / 2 b))$ have a distant location of the cleaving groups relative to the target site (Figure 7 shows F5$\operatorname{Im}(4 / 2 b))$. Moreover, only one of two bis-imidazole groups can occupy a position, favorable for cleaving activity. This decreases the statistical probability of reaching an "active" conformation for M-Im(4/2b). Generally, most of the final structures of $\mathrm{M}-\operatorname{Im}(4 / 2 \mathrm{~b})$ are characterized by long distances between imidazole rings and target atoms. Analysis of the structural parameters showed that the length of the linker group is not enough to provide a good chance to reach the target site. This possibly contributes to the restricted conformational freedom caused by thymidine interactions with the RNA:DNA duplex structure (see above for M$\operatorname{Im}(4 / 2 \mathrm{a}))$. Taken together, these explain the lowest hydrolytic activity for B-Im(4/2b) between the artificial ribonucleases.

Analysis of final structures resulting from the simulating annealing experiments shows a remarkable ability of all cleaving constructs to form multiple hydrogen bonds that generally can be represented by two types (Scheme 1). The first type is the intermolecular interactions between cleaving constructs and the RNA target, which are formed by oxygen atoms of the RNA phosphate backbone and either (i) by imidazole rings of the cleaving groups or (ii) by protons of the linker amido groups (see Scheme 1). These types of hydrogen bonding seem to be in favor of the hydrolytic activity of compounds due to their ability to stabilize the location of cleaving groups, close to the RNA target. The second type of possible hydrogen bonding (Scheme 1) refers to intramolecular interactions within cleaving constructs themselves and involves interactions between imidazole rings and amido groups, carbonyl groups and phosphate groups of the linker. This type of hydrogen bond interaction also includes intralinker bridges formed by amido and carbonyl/ phosphate groups. Intramolecular hydrogen bonds seem to compete with favorable intermolecular interactions, preventing the imidazole groups from appropriate contacts with 


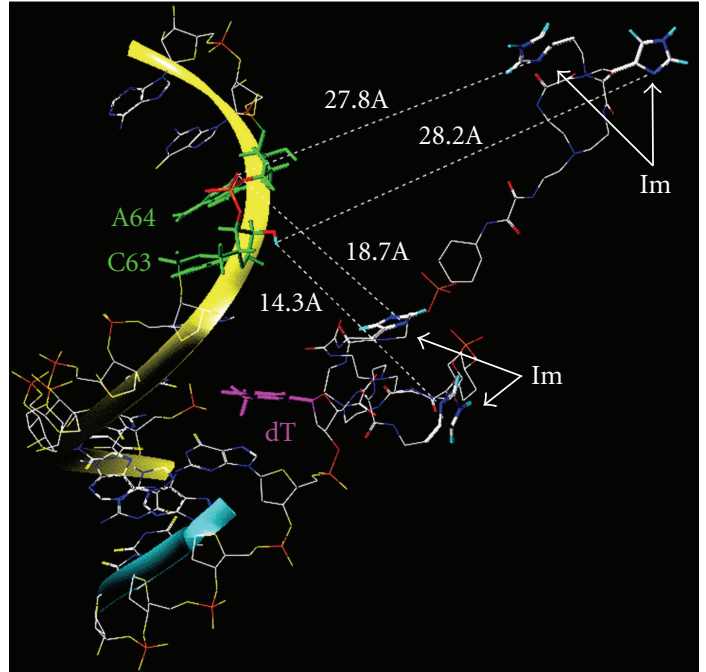

FIGURE 6: A fragment showing one possible conformation (namely, final structure $\mathrm{F} 9-\operatorname{Im}(4 / 2 \mathrm{a})$ ) of $\mathrm{B}-\operatorname{Im}(4 / 2 \mathrm{a})$ (4a) found for the hybrid complex H-Im(4/2a). Distances between the cleaving groups and the sequence $\mathrm{C}^{63}-\mathrm{A}^{64}$ (green) are indicated. The $\mathrm{dT}$ (magenta) semistacking interaction with the $\mathrm{dG}^{1}$ fragment is also shown. Hydrogen atoms have been removed for easier visualization.

the RNA backbone, which may result in a decrease of their hydrolytic activity.

Based on these results, we propose several suggestions on how to improve further the cleaving potential of artificial ribonucleases. First, it is important to avoid the use of any carbonyl/phosphate groups within the linker in order to decrease the possibility of intramolecular hydrogen bonding. Secondly, it could be advantageous to introduce polycationic groups within the linker, which might increase possible contacts of cleaving groups with negatively charged phosphate backbones of target RNA. Finally, the insertion of a suitable hydrophobic/intercalating groups within the linker might also increase chances for these groups to be located in the vicinity of the RNA target due to additional stacking/ hydrophobic interactions with different ribonucleotide environments.

\section{Conclusions}

In the current research, we studied oligonucleotide-based artificial ribonucleases containing multiple imidazole residues in the catalytic part of the aRNases with systematically varied structure of cleaving constructs. All the conjugates contain the same addressing oligonucleotide which provides efficient and almost quantitative binding of the conjugates to the target sequence within the tRNA. This allows comparing different cleaving constructs in terms of site specificity and efficiency of RNA cleavage. Obtained results let us conclude that the efficiency of site-selective RNA cleavage is governed by a number of dynamic parameters among which the most important is the flexibility of a linker between the catalytic imidazole residues and the addressing oligonucleotide. The other factors affecting the efficiency of site-selective RNA cleavage are the number of imidazole residues in the catalytic

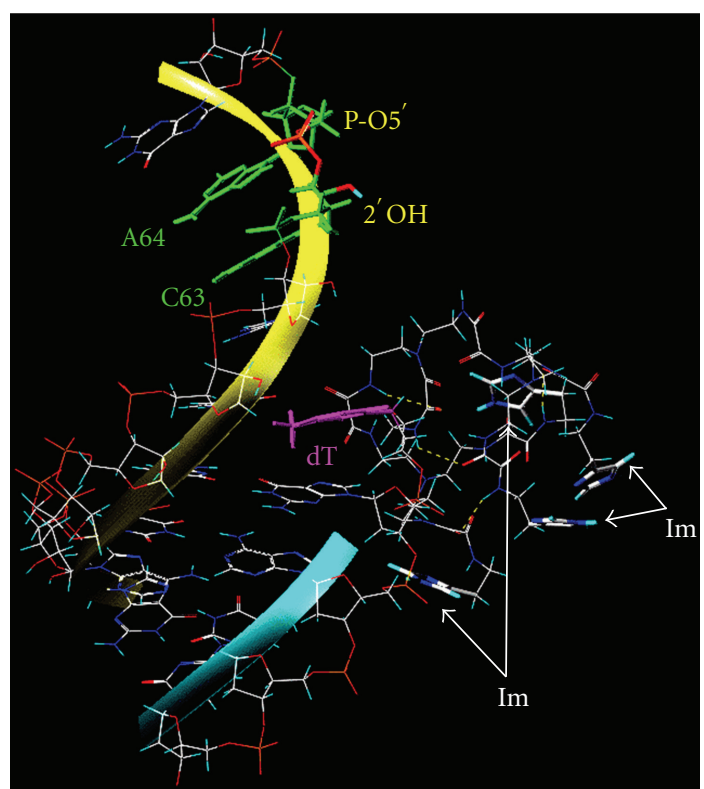

Figure 7: A fragment showing one possible conformation for the hybrid complex between artificial ribonuclease B-Im(4/2b) and tRNA. In this final conformation, F5- $\operatorname{Im}(4 / 2 \mathrm{~b})$, the imidazole cleaving groups are located distant from the target sequence. The dT linker fragment (magenta) shows interaction with the $\mathrm{dG}^{1}$ residue in a semi-stacking interaction, possibly restricting the conformational freedom of this molecule. Hydrogen bonds are shown in yellow.

part, the type of anchor group, connecting linker structure and the oligonucleotide, and the length of a linker between the catalytic imidazole groups of the construct and the oligonucleotide. We found that four imidazole residues located in the catalytic part of the conjugate can efficiently catalysed cleavage of phosphodiester bond in the case when they are located in the close proximity of RNA sugar-phosphate backbone, while increasing of the number of imidazole groups inhibits cleavage, possibly due to steric interference between the imidazole residues.

Molecular modeling carried out to explain differences in ribonuclease activity of the conjugates showed that preferable orientation(s) of cleaving constructs strongly depend on the structure of the anchor group and length of the linker. The inclusion of deoxyribothymidine as an anchor group significantly reduced the probability of cleaving groups to locate near the cleavage site due to a stacking interaction with the neighbouring nucleotide residue. Remarkably high cleavage activity was displayed by the conjugates with the most flexible and extended cleaving construct, which presumably provides a better opportunity for imidazole residues to be correctly positioned in the vicinity of scissile phosphodiester bond.

The other very important factor affecting the efficiency of site-selective RNA cleavage is sensitivity of phosphodiester bonds of RNA toward cleavage. Different catalytic structures display some sequence preference [1]. On the other hand, phosphodiester bonds in different RNA sequence display different sensitivities to cleaving agents [3, 44-48]. These factors should be taken into account when selecting target 
sites within specific RNAs. In our experiments, the cleaving groups were targeted to CACA sequence of $\mathrm{tRNA}^{\text {Phe }}$, known to be of particular sensitivity to cleavage by different agents. So, the ribonuclease activity of the conjugates was compared under favourable conditions. On the other hand, binding of oligonucleotide conjugates to target RNA is followed by RNA structure rearrangements that can bring the target site in favorable or unfavorable positions toward the catalytic groups $[32,49,50]$. Thus, optimisation of the structure of catalytic groups of oligonucleotide conjugates and identification of optimal structures of RNA for targeting with artificial ribonucleases may facilitate the creation of highly specific artificial ribonucleases of a new generation.

Results of the studies performed by the authors revealed the problems to be solved in order to develop the highly efficient RNA cleaving oligonucleotide conjugates. A few important factors determining efficacy of RNA cleavage remain to be investigated so that the oligonucleotide conjugates take advantage of the known mechanisms used by natural enzymes for achieving high reaction rate.

\section{Acknowledgments}

This work was supported by the grants from The Welcome Trust (no. 063630), RFBR (nos. 02-04-48664 and 03-0406238), RAS program "Molecular and cellular biology," Ministry of Science and Education of the Russian Federation (state contract P438), and President's Program in support of leading scientific schools SS-7101.2010.4.

\section{References}

[1] M. A. Zenkova and N. G. Beloglazova, "Site-specific artificial ribonucleases: conjugates of oligonucleotides with catalytic groups," in Nucleic Acids and Molecular Biology: Artificial Nucleases, M. A. Zenkova, Ed., vol. 13, pp. 189-222, Springer, Berlin, Germany, 2004.

[2] V. N. Sil'nikov and V. V. Vlassov, "Design of site-specific RNAcleaving reagents," Russian Chemical Reviews, vol. 70, no. 6, pp. 491-508, 2001.

[3] H. Lönnberg, "Cleavage of RNA phosphodiester bonds by small molecular entities: a mechanistic insight," Organic and Biomolecular Chemistry, vol. 21, pp. 1687-1703, 2011.

[4] G. N. Grimm, A. S. Boutorine, and C. Hélène, "Rapid routes of synthesis of oligonucleotide conjugates from non-protected oligonucleotides and ligands possessing different nucleophilic or electrophilic functional groups," Nucleosides, Nucleotides and Nucleic Acids, vol. 19, no. 10-12, pp. 1943-1965, 2000.

[5] A. S. Modak, J. K. Gard, M. C. Merriman, K. A. Winkeler, J. K. Bashkin, and M. K. Stern, "Toward chemical ribonucleases 2. Synthesis and characterization of nucleoside-bipyridine conjugates. Hydrolytic cleavage of RNA by their copper(II) complexes," Journal of the American Chemical Society, vol. 113, no. 1, pp. 283-291, 1991.

[6] J. K. Bashkin, J. Xie, A. T. Daniher, U. Sampath, and J. L. F. Kao, "Building blocks for ribozyme mimics: conjugates of terpyridine and bipyridine with nucleosides," Journal of Organic Chemistry, vol. 61, no. 7, pp. 2314-2321, 1996.
[7] J. Hovinen, "Synthesis of carbon-3-substituted 1,5,9-triazacyclododecanes, RNA cleavage agents suitable for oligonucleotide tethering," Bioconjugate Chemistry, vol. 9, no. 1, pp. 132-136, 1998.

[8] H. Inoue, M. Shimizu, T. Furukawa, T. Tamura, M. Matsui, and E. Ohtsuka, "Site-specific RNA cleavage using terpyridine - $\mathrm{Cu}(\mathrm{II})$-linked 2'-O- methyloligonucleotides," Nucleosides and Nucleotides, vol. 18, no. 6-7, pp. 1503-1505, 1999.

[9] J. K. Bashkin, E. I. Frolova, and U. Sampath, "Sequencespecific cleavage of HIV mRNA by a ribozyme mimic," Journal of the American Chemical Society, vol. 116, no. 13, pp. 59815982, 1994.

[10] T. H. Smith, J. V. LaTour, D. Bochkariov, G. Chaga, and P. S. Nelson, "Bifunctional phosphoramidite reagents for the introduction of histidyl and dihistidyl residues into oligonucleotides," Bioconjugate Chemistry, vol. 10, no. 4, pp. 647-652, 1999.

[11] D. M. Perrin, T. Garestier, and C. Hélène, "Bridging the gap between proteins and nucleic acids: a metal-independent RNAse A mimic with two protein-like functionalities," Journal of the American Chemical Society, vol. 123, no. 8, pp. 15561563, 2001.

[12] N. G. Beloglazova, N. N. Polushin, V. N. Sil'nikov, M. A. Zenkova, and V. V. Vlassov, "Site selective cleavage of yeast tRNA $^{\text {Phe }}$ by conjugates of antisense oligonucleotide with imidazole containing cleaving groups," Doklady Academii Nauk, vol. 369, no. 6, pp. 827-830, 1999.

[13] L. Yurchenko, V. Silnikov, T. Godovikova, G. Shishkin, J. J. Toulme, and V. Vlassov, "Cleavage of Leishmania mini-exon sequence by oligonucleotides conjugated to a diimidazole construction," Nucleosides and Nucleotides, vol. 16, no. 7-9, pp. 1721-1725, 1997.

[14] V. Vlassov, T. Abramova, T. Godovikova, R. Giege, and V. Silnikov, "Sequence-specific cleavage of yeast tRNA ${ }^{\text {Phe }}$ with oligonucleotides conjugated to a diimidazole construct," Antisense and Nucleic Acid Drug Development, vol. 7, no. 1, pp. 3942, 1997.

[15] K. Ushijima, H. Gouzu, K. Hosono et al., "Site-specific cleavage of tRNA by imidazole and/or primary amine groups bound at the $5^{\prime}$-end of oligodeoxyribonucleotides," Biochimica et Biophysica Acta, vol. 1379, no. 2, pp. 217-223, 1998.

[16] V. Silnikov, G. Zuber, J. P. Behr, R. Giege, and V. Vlassov, "Design of ribonuclease mimics for sequence specific cleavage of RNA," Phosphorus, Sulfur and Silicon and Related Elements, vol. 109-110, no. 1-4, pp. 277-280, 1996.

[17] J. Hovinen, A. Guzaev, E. Azhayeva, A. Azhayev, and H. Lönnberg, "Imidazole tethered oligodeoxyribonucleotides: synthesis and RNA cleaving activity," Journal of Organic Chemistry, vol. 60, no. 7, pp. 2205-2209, 1995.

[18] A. Y. Karyagin, T. V. Abramova, V. N. Sil'nikov, and G. V. Shishkin, "Reagents for addressed modification of biopolymers," Russian Chemical Bulletin, vol. 49, no. 3, pp. 540-545, 2000.

[19] M. A. Reynolds, T. A. Beck, P. B. Say et al., "Antisense oligonucleotides containing an internal, non-nucleotide-based linker promote site-specific cleavage of RNA," Antisense and Nucleic Acid Drug Development, vol. 24, no. 4, pp. 760-765, 1996.

[20] M. Endo, Y. Azuma, Y. Saga, A. Kuzuya, G. Kawai, and M. Komiyama, "Molecular design for a pinpoint RNA scission. Interposition of oligoamines between two DNA oligomers," Journal of Organic Chemistry, vol. 62, no. 4, pp. 846-852, 1997. 
[21] N. N. Polushin, "The precursor strategy: terminus methoxyoxalamido modifiers for single and multiple functionalization of oligodeoxyribonucleotides," Nucleic Acids Research, vol. 28, no. 16, pp. 3125-3133, 2000.

[22] A. M. Morocho and N. N. Polushin, "Methoxyoxalamido chemistry in the synthesis of tethered phosphoramidites and functionalized oligonucleotides," Current Protocols in Nucleic Acid Chemistry, vol. chapter 4, p. unit 4.29, 2006.

[23] N. G. Beloglazova, N. N. Polushin, V. N. Sil'nikov, M. A. Zenkova, and V. V. Vlasov, "Site-specific cleavage of yeast tRNA(Phe) by derivatives of oligonucleotides bearing bisimidazole groups," Doklady Akademii Nauk, vol. 369, no. 6, pp. 827-830, 1999.

[24] N. G. Beloglazova, M. M. Fabani, M. A. Zenkova et al., "Sequence-specific artificial ribonucleases. I. Bis-imidazolecontaining oligonucleotide conjugates prepared using precursor-based strategy," Nucleic Acids Research, vol. 32, no. 13, pp. 3887-3897, 2004.

[25] S. Nishikawa, H. Morioka, H. J. Kim et al., "Two histidine residues are essential for ribonuclease $\mathrm{T} 1$ activity as is the case for ribonuclease A," Biochemistry, vol. 26, no. 26, pp. 8620 8624, 1987.

[26] A. Wlodawer, M. Miller, and L. Sjölin, "Active site of RNase: neutron diffraction study of a complex with uridine vanadate, a transition-state analog," Proceedings of the National Academy of Sciences of the United States of America, vol. 80, no. 12, pp. 3628-3631, 1983.

[27] L. Vitagliano, A. Merlino, A. Zagari, and L. Mazzarella, "Productive and nonproductive binding to ribonuclease A: X-ray structure of two complexes with uridylyl $\left(2,5^{\prime}\right)$ guanosine," Protein Science, vol. 9, no. 6, pp. 1217-1225, 2000.

[28] M. Komiyama and T. Inokawa, "Selective hydrolysis of tRNA by ethylenediamine bound to a DNA oligomer," Journal of Biochemistry, vol. 116, no. 4, pp. 719-720, 1994.

[29] R. Giegé, B. Felden, M. A. Zenkova, V. N. Sil'nikov, and V. V. Vlassov, "Cleavage of RNA with synthetic ribonuclease mimics," Methods in Enzymology, vol. 318, pp. 147-165, 2000.

[30] M. Zenkova, N. Beloglazova, V. Sil'nikov, V. Vlassov, and R. Giegë, "RNA cleavage by 1,4-diazabicyclo[2.2.2] octane-imidazole conjugates," Methods in Enzymology, vol. 341, pp. 468490, 2001.

[31] N. G. Beloglazova, V. N. Sil'Nikov, M. A. Zenkova, and V. V. Vlassov, "Cleavage of yeast tRNA ${ }^{\text {Phe }}$ with complementary oligonucleotide conjugated to a small ribonuclease mimic," Federation of European Biochemical Societies Letters, vol. 481, no. 3, pp. 277-280, 2000.

[32] N. V. Tamkovich, A. N. Zenkov, V. V. Vlasov, and M. A. Zenkova, "An RNA sequence determines the speed of its cleavage by artificial ribonucleases," Russian Journal of Bioorganic Chemistry, vol. 36, no. 2, pp. 207-218, 2010.

[33] V. A. Petyuk, M. A. Zenkova, R. Giege, and V. V. Vlassov, "Hybridization of antisense oligonucleotides with the 3' part

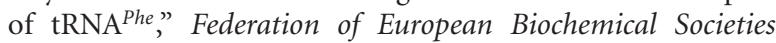
Letters, vol. 444, no. 2-3, pp. 217-221, 1999.

[34] V. Petyuk, R. Serikov, V. Tolstikov et al., "Invasion of strongly binding oligonucleotides into tRNA structure," Nucleosides, Nucleotides and Nucleic Acids, vol. 19, no. 7, pp. 1145-1158, 2000.

[35] R. N. Serikov, V. A. Petyuk, V. V. Vlassov, and M. A. Zenkova, "Hybridization of antisense oligonucleotides with yeast tRNA $^{\text {Phe }}$ : factors determining the efficiency of interaction," Russian Chemical Bulletin, vol. 51, no. 7, pp. 1156-1165, 2002.
[36] A. V. Vlasov, V. V. Vlasov, and R. Giege, "RNA hydrolysis catalyzed by imidazole as a reaction for studying the secondary structure of RNA and complexes of RNA with oligonucleotides," Doklady Akademii Nauk, vol. 349, no. 3, pp. 411413, 1996.

[37] N. G. Beloglazova, A. Y. Epanchintsev, V. N. Sil'nikov, M. A. Zenkova, and V. V. Vlasov, "Highly effective site-selective cleavage of RNA by imidazoles-containing antisense oligonucleotide conjugates," Molecular Biology, vol. 36, no. 4, pp. 731-739, 2002.

[38] Y. Kumazawa, T. Yokogawa, H. Tsurui, K. Miura, and K. Watanabe, "Effect of the higher-order structure of tRNAs on the stability of hybrids with oligodeoxyribonucleotides: separation of tRNA by an efficient solution hybridization," Nucleic Acids Research, vol. 20, no. 9, pp. 2223-2232, 1992.

[39] I. Zegers, D. Maes, M. H. Dao-Thi, F. Poortmans, R. Palmer, and L. Wyns, "The structures of RNase A complexed with 3'CMP and $\mathrm{d}(\mathrm{CpA})$ : active site conformation and conserved water molecules," Protein Science, vol. 3, no. 12, pp. 23222339, 1994.

[40] C. F. Aguilar, P. J. Thomas, D. S. Moss, A. Mills, and R. A. Palmer, "Novel non-productively bound ribonuclease inhibitor complexes-high resolution X-ray refinement studies on the binding of RNAse-A to cytidylyl-2,5'-guanosine (2',5'CpG) and deoxycytidylyl-3',5'-guanosine (3',5' dCpdG)," Biochimica et Biophysica Acta, vol. 1118, no. 1, pp. 6-20, 1991.

[41] C. F. Aguilar, P. J. Thomas, A. Mills, D. S. Moss, and R. A. Palmer, "Newly observed binding mode in pancreatic ribonuclease," Journal of Molecular Biology, vol. 224, no. 1, pp. 265267, 1992.

[42] J. C. Fontecilla-Camps, R. de Llorens, M. H. le Du, and C. M. Cuchillo, "Crystal structure of ribonuclease A.d(Ap TpApApG) complex. Direct evidence for extended substrate recognition," Journal of Biological Chemistry, vol. 269, no. 34, pp. 21526-21531, 1994.

[43] D. L. Birdsall and A. McPherson, "Crystal structure of ribonuclease A·d(ApTpApApG) complex. Direct evidence for extended substrate recognition," Journal of Biological Chemistry, vol. 267, no. 31, pp. 22230-22236, 1992.

[44] R. Kierzek, "Structural consideration concerning cleavage of RNA," in Nucleic Acids and Molecular Biology: Artificial Nucleases, M. A. Zenkova, Ed., vol. 13, pp. 33-48, Springer, Berlin, Germany, 2004.

[45] I. Zagórowska, S. Kuusela, and H. Lönnberg, "Metal iondependent hydrolysis of RNA phosphodiester bonds within hairpin loops. A comparative kinetic study on chimeric ribo/ 2'-O-methylribo oligonucleotides," Nucleic Acids Research, vol. 26, no. 14, pp. 3392-3396, 1998.

[46] I. Zagorowska, S. Mikkola, and H. Lönnberg, "Hydrolysis of phosphodiester bonds within RNA hairpin loops in buffer solutions: the effect of secondary structure on the inherent reactivity of RNA phosphodiester bonds," Helvetica Chimica Acta, vol. 82, no. 12, pp. 2105-2111, 1999.

[47] S. Mihkola, U. Kaukinen, and H. Lönnberg, "The effect of secondary structure on cleavage of the phosphodiester bonds of RNA," Cell Biochemistry and Biophysics, vol. 34, no. 1, pp. 95-119, 2001.

[48] U. Kaukinen, S. Lyytikäinen, S. Mikkola, and H. Lönnberg, "The reactivity of phosphodiester bonds within linear singlestranded oligoribonucleotides in strongly dependent on the base sequence," Nucleic Acids Research, vol. 30, no. 2, pp. 468474, 2002. 
[49] R. Häner, J. Hall, A. Pfützer, and D. Hüsken, "Development of artificial ribinucleases," Pure and Applied Chemistry, vol. 70, no. 1, pp. 111-116, 1998.

[50] R. Serikov, V. Petyuk, Y. Vorobijev et al., "Mechanism of antisense oligonucleotide interaction with natural RNAs," Journal of Biomolecular Structure and Dynamics, vol. 29, no. 1, pp. 2750, 2011. 

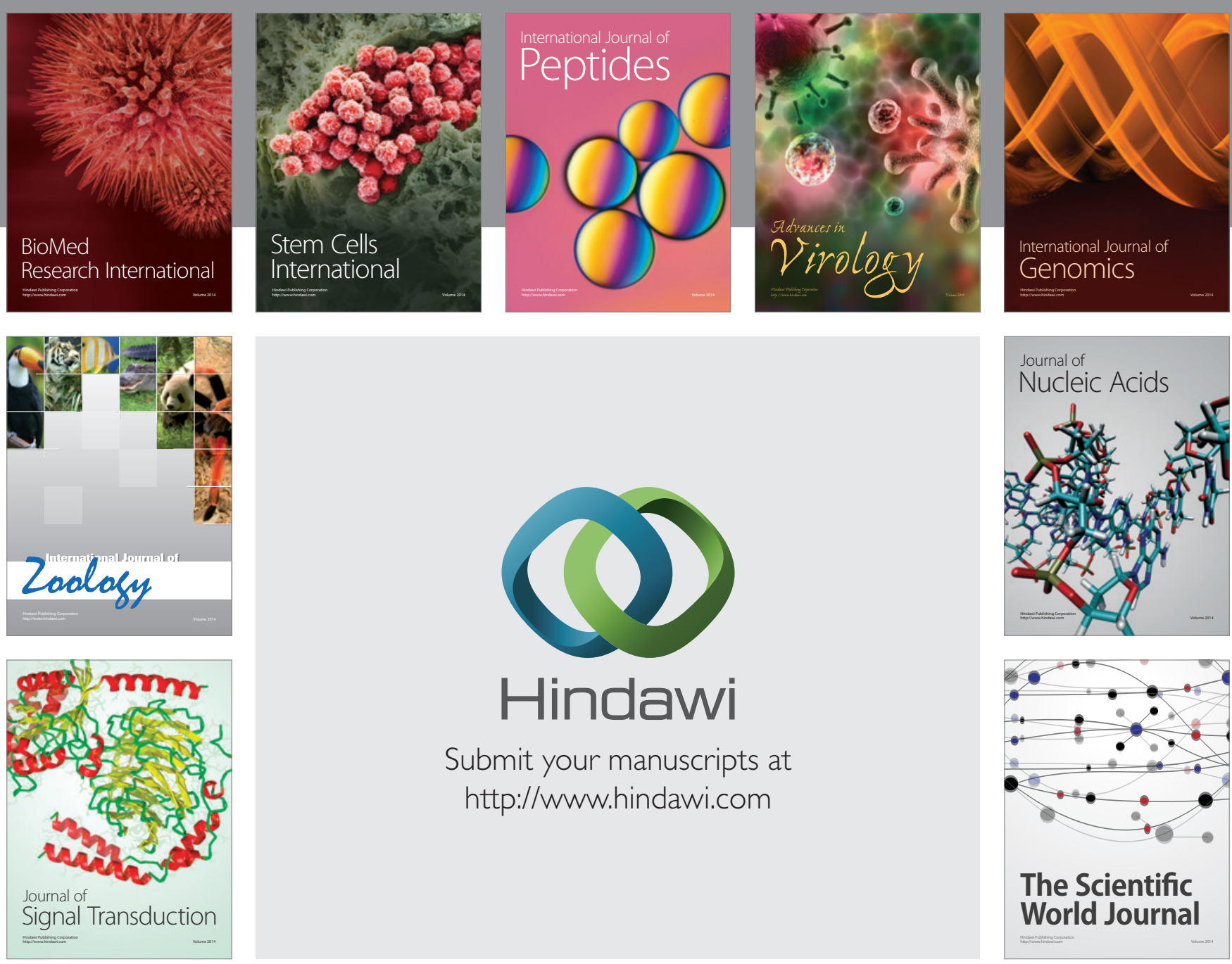

Submit your manuscripts at

http://www.hindawi.com
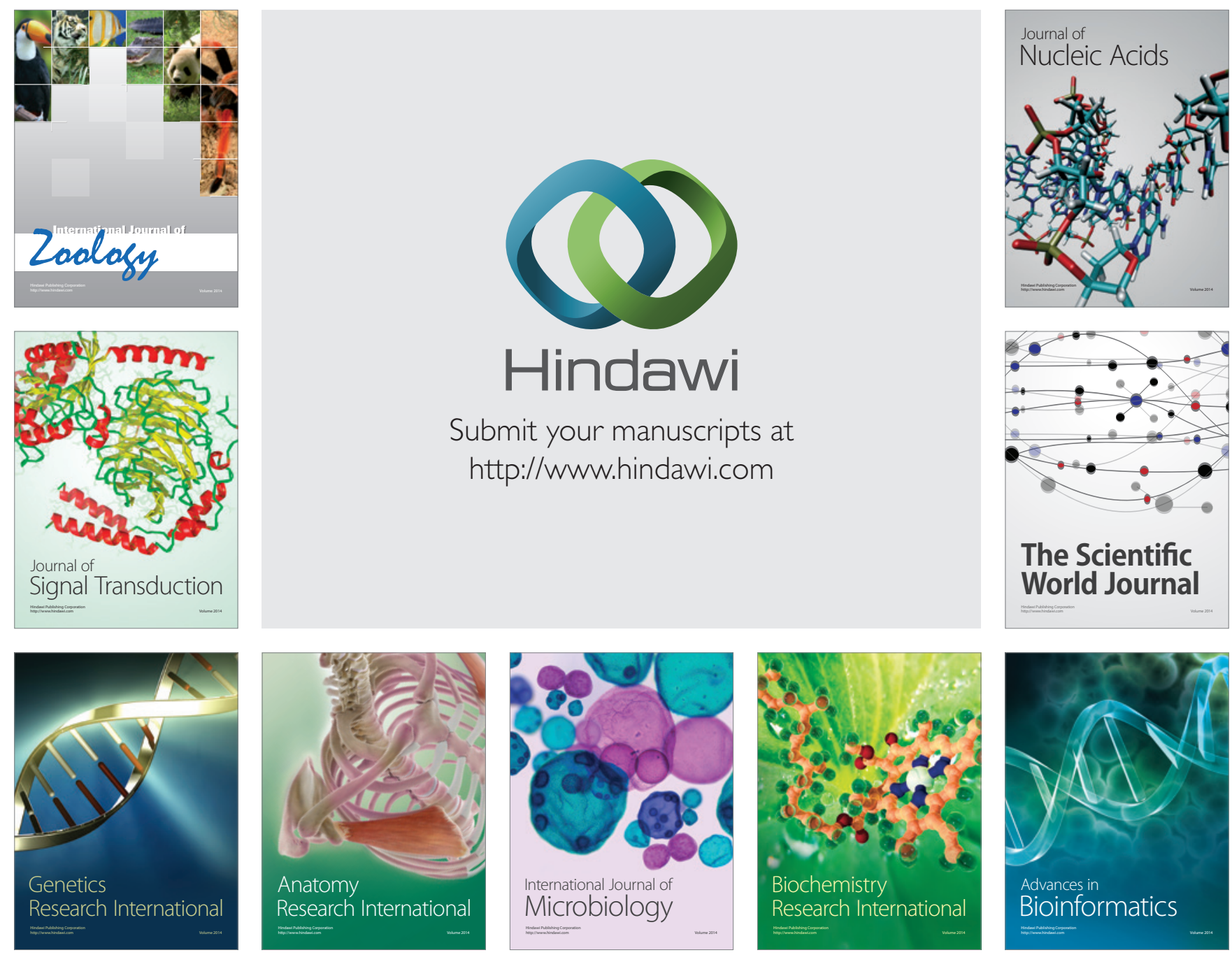

The Scientific World Journal
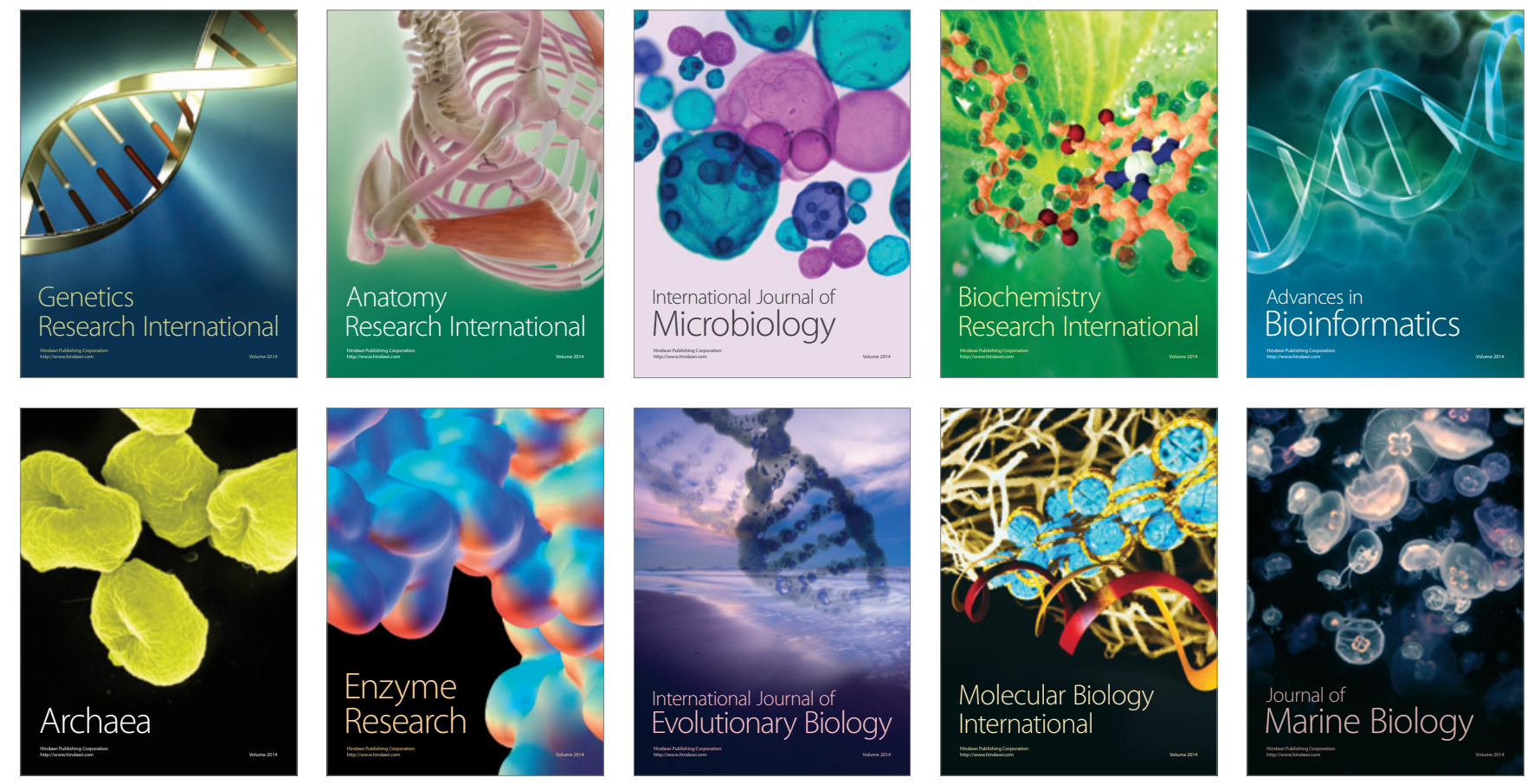